\title{
Nitric oxide is cytoprotective to breast cancer spheroids vulnerable to estrogen-induced apoptosis
}

\author{
Yana Shafran ${ }^{1, *}$, Naomi Zurgil ${ }^{1, *}$, Orit Ravid-Hermesh ${ }^{1}$, Maria Sobolev ${ }^{1}$, Elena \\ Afrimzon ${ }^{1}$, Yaron Hakuk ${ }^{1}$, Asher Shainberg ${ }^{2}$ and Mordechai Deutsch ${ }^{1}$ \\ ${ }^{1}$ The Biophysical Interdisciplinary Jerome Schottenstein Center for the Research and Technology of the Cellome, Physics \\ Department, Bar Ilan University, Ramat Gan 52900, Israel \\ ${ }^{2}$ The Mina and Everard Goodman Faculty of Life Sciences, Bar Ilan University, Ramat Gan 52900, Israel \\ *These authors have contributed equally to this work \\ Correspondence to: Mordechai Deutsch, email: motti.jsc@gmail.com \\ Keywords: nitric oxide; breast cancer spheroids; estrogen-induced apoptosis; estrogen receptor-positive; live-cell imaging \\ Received: February 15, $2017 \quad$ Accepted: August 17, $2017 \quad$ Published: October 07, 2017 \\ Copyright: Shafran et al. This is an open-access article distributed under the terms of the Creative Commons Attribution License \\ 3.0 (CC BY 3.0), which permits unrestricted use, distribution, and reproduction in any medium, provided the original author and \\ source are credited.
}

\section{ABSTRACT}

Estrogen-induced apoptosis has become a successful treatment for postmenopausal metastatic, estrogen receptor-positive breast cancer. Nitric oxide involvement in the response to this endocrine treatment and its influence upon estrogen receptor-positive breast cancer progression is still unclear.

Nitric oxide impact on the MCF7 breast cancer line, before and after estrogeninduced apoptosis, was investigated in 3D culture systems using unique live-cell imaging methodologies.

Spheroids were established from MCF7 cells vulnerable to estrogen-induced apoptosis, before and after exposure to estrogen.

Spheroids derived from estrogen-treated cells exhibited extensive apoptosis levels with downregulation of estrogen receptor expression, low proliferation rate and reduced metabolic activity, unlike spheroids derived from non-treated cells. In addition to basic phenotypic differences, these two cell cluster types are diverse in their reactions to exogenous nitric oxide.

A dual effect of nitric oxide was observed in the breast cancer phenotype sensitive to estrogen-induced apoptosis. Nitric oxide, at the nanomolar level, induced cell proliferation, high metabolic activity, downregulation of estrogen receptor and enhanced collective invasion, contributing to a more aggressive phenotype. Following hormone supplementation, breast cancer 3D clusters were rescued from estrogeninduced apoptosis by these low nitric oxide-donor concentrations, since nitric oxide attenuates cell death levels, upregulates survivin expression and increases metabolic activity.

Higher nitric oxide concentrations (100nM) inhibited cell growth, metabolism and promoted apoptosis. These results suggest that nitric oxide, in nanomolar concentrations, may inhibit estrogen-induced apoptosis, playing a major role in hormonal therapy. Inhibiting nitric oxide activity may benefit breast cancer patients and ultimately reduce tumor recurrence. 


\section{INTRODUCTION}

Breast cancer $(\mathrm{BC})$ occurs in both women and men, and its incidence increases with age. $\mathrm{BC}$ is the most frequently diagnosed cancer among women, and the leading cause of cancer-related death worldwide [1].

Estrogen receptor (ER), detected in approximately 70 to $80 \%$ of primary BCs, regulates endocrine-dependent growth in these tumors. Expression of ER often mediates sensitivity of tumor cells to hormonal treatment. Hormonal manipulation is achieved either at a cellular level by using anti-estrogens, such as tamoxifen, to compete for ER in the breast tumor, or systemically, by lowering estrogen levels in premenopausal women by the use of luteinizing hormone-releasing hormone agonists and in postmenopausal women by aromatase inhibitors that block estrogen biosynthesis in non-ovarian tissues. These endocrine therapies are very effective as treatment for ER-positive BC, and for patients with early-stage disease, hormonal therapy given for five years after primary surgery markedly delays local and distant relapse and prolongs overall survival $[2,3]$. Despite major therapeutic success, the strategies of long term anti-hormone therapies eventually lead to a significant proportion of anti-hormone resistant or stimulated tumor growth and failure of therapy is observed in $20-25 \%$ of patients who exhibit intrinsic or acquired resistance $[4,5]$. These patients ultimately demonstrate further disease progression that may lead to outgrowth of metastases in distant organs and cancerrelated death [6]. Much progress has been made in understanding the molecular biology associated with secondary endocrine resistance.

Interestingly, it was discovered that the cell populations which emerge and grow after long-term antihormone treatment are vulnerable to the cytotoxicity of estrogen-induced apoptosis. Hence, BC cell growth and $\mathrm{BC}$ cell apoptosis are both regulated via the ER. As a result, estrogen-induced apoptosis becomes a successful treatment for postmenopausal metastatic, ER-positive BC women [7-9]. The mechanism by which estrogens are able to induce apoptosis was suggested to be selection of $\mathrm{BC}$ populations that are resistant to long-term estrogen deprivation, and are vulnerable to physiologic estrogen that triggers apoptosis and tumor regression [7, 10]. Another mechanism, which is proposed by Suba in [11], is compensatory restoration of ER-signaling by estrogen, which prompts apoptotic death of tumor cells. It has been implied that estrogen withdrawal or ER blockade, induced acquired estrogen hypersensitivity which is attributed to ER overexpression and high $17 \beta$-estradiol (E2) synthesis, even after long-term antiestrogen therapy, resulting in apoptotic death of tumor cells $[11,12]$.

In order to amplify and enhance hormone-induced apoptosis, targeted strategies to inhibit cell survival pathways are now required [13]. This calls for specially designed, advanced cellular models and tailored assays which more accurately reproduce the in vivo complexity of $\mathrm{BC}$ cells and tumor microenvironment.

Cellular models of $\mathrm{BC}$ are being utilized in the laboratory to mimic the clinical status of hormoneresistant breast tumor, and function as tools to discover new therapeutic strategies. Several MCF7 BC lines were generated, based on their sensitivity to estrogen-induced apoptosis, either via long-term deprivation [14] or by induction of antiestrogen (tamoxifen) resistance [15]. In spite of some differences between the various lines, all showed apoptosis induction following exposure to low physiologic concentrations of estrogen, increased ER levels, and marked translocation of ER from the nucleus into the cytoplasm [16].

The action of E2 by ER is known to elicit nitric oxide (NO) signaling via activation of NO synthase (NOS) in many tissues. NOS is often elevated in breast tumors that lack expression of the ER, and has been proved to be a key driver of signaling pathways in ER-negative $\mathrm{BC}$, which promotes tumor growth, metastasis and drug resistance [17].

However, the involvement of NO in the response to endocrine treatment in general, and especially to estrogen-induced apoptosis, as well as its contribution to ER-positive $\mathrm{BC}$ aggressiveness is still unclear.

Utilizing advanced cellular models, this study aims to investigate the role of $\mathrm{NO}$ in the response to this endocrine treatment, (e.g. estrogen-induced apoptosis) of ER-positive BC cells, in order to better understand, and ultimately reduce, tumor recurrence.

BC spheroids were established from MCF7 cells vulnerable to estrogen-induced apoptosis, before and after exposure to the hormone, and their response to exogenous NO was examined via live-cell imaging tools.

\section{RESULTS}

\section{MCF7 cells vulnerable to estrogen-induced apoptosis before and after exposure to E2}

Bright field and fluorescence images of MCF7 cells grown in 2D culture, prior to and following exposure to E2 are depicted in Figure 1. Before hormonal treatment, MCF7 cells proliferate and develop homogeneous monolayer (Figure 1A). The doubling time of this phenotype is about $35.5 \mathrm{~h}$, and the percent of Annexin V and propidium iodide (PI)-positive cells was negligible. $(1.2 \pm 0.13 \%$ and $1.1 \pm 0.1 \%$ for apoptosis and cell death signals, respectively) (Figure 1B). Upon addition of $10 \mathrm{nM}$ E2 to culture medium, in the course of two weeks the MCF7 BC cells undergo a slow morphological shift. Following 5 passages in the presence of medium supplemented with E2, a dramatic cell detachment is evident, the cells grow in multilayer structures (Figure 1C) and extensive apoptosis is apparent (Figure 1D). The average area stained for Annexin V reaches $48.5 \pm 7.7 \%$ 
and the doubling time of the cells is $50.5 \mathrm{~h}$, which is slower in comparison to that of non-treated cells. Concomitantly, cell death levels increased, but remained low (percent of PI stained area was $2.2 \pm 1.4 \%$ ). Hence, hormonal treatment induced high levels of apoptosis and the cells were proliferating at a lower rate (Figure 1E). Upon additional culturing of the cells in the presence of E2, almost all the cells become detached from the culture plate and a remarkable decrease in cell number (up to 90\%) is observed (data not shown).

The differences between the two cell phenotypes accompanied substantial variation in $\mathrm{ER} \alpha$ status. Two weeks after E2-induced apoptosis, downregulation of $\mathrm{ER} \alpha$ expression levels was evident, and the protein was no longer detectable by western blotting analysis (Figure 1F).

This data is in agreement with previous results by Pink et al [18], which presented a model of ER regulation in MCF7 line that involves upregulation of ER mRNA and protein in an estrogen-depleted environment, but ER is downregulated in the presence of estrogen.

\section{Generation and growth of spheroids from MCF7 cells before and after exposure to $\mathrm{E} 2$}

BC spheroids were generated from MCF7 cells vulnerable to estrogen-induced apoptosis within hydrogel microchamber (HMC) arrays as described [19]. Individual MCF7 cells before and two weeks after hormonal treatment were seeded within HMC array and allowed to create cell clusters during $48 \mathrm{~h}$. Spontaneous creation of 3D multicellular spheroids within hydrogel array is shown in Supplementary Videos 1 and 2 (see Supplementary Materials) and Figure 2A.

During the first day after seeding, individual cells aggregate and form multicellular clusters, which continue to grow in the following days, each in an individual microchamber (MC). Both spheroid phenotypes display compact multicellular structures filled with cells, without cavities or hollows. Calculation of the number of cells comprising each spheroid showed that the increase in spheroid sectional area is associated with a parallel elevation in cell number, and hence correlates with the proliferation rate of the 3D structures (see Supplementary Material 1).

After cell seeding, due to the non-adherent nature of the hydrogel, cells retain their spherical/globular structure and their dimensions can be estimated from the bright field images (see Methods and Supplementary Material 1). At $t=0$, the average cell size of hormonetreated cells was significantly larger than that of MCF7 non-treated cells (Figure 2A). The corresponding average cell volumes were $1.69 \pm 0.81 \mathrm{pL}$ and $2.79 \pm 1.37 \mathrm{pL}$ with $\mathrm{p}<0.0001$, for $\mathrm{BC}$ cells prior to and following exposure to E2, respectively. Representative 2-day BC spheroids spontaneously generated within HMC array from nontreated and E2-treated MCF7 cells are shown in Figure
2B. The correlation between number of cells per $\mathrm{MC}$ and size of the subsequently formed spheroids is shown in Figure 2C. High correlation was found between the number of cells per microchamber and the sectional area of the corresponding spheroids at day 2 for both spheroid populations (Pearson correlation $=0.69$ and 0.84 for spheroids derived from MCF7 cells before and after E2 treatment, respectively). Moreover, for both 3D phenotypes, the relative growth ratio (the ratio between spheroid sectional areas at two time points) of individual spheroids was not dependent on the initial number of cells per single MC (Figure 2D). Under the experimental conditions described herein (mean cell number per $\mathrm{MC}$ was $15 \pm 5.2$ ), the average sectional area of $48 \mathrm{~h}$ spheroids derived from MCF7 cells before E2 exposure was $4900 \pm 2450 \mu \mathrm{m}^{2}$, similar to the size of spheroids derived from hormone-treated cells $\left(4880 \pm 1950 \mu \mathrm{m}^{2}\right)$. However, since individual cells within two spheroid phenotypes retained their size differences, the MCF7 cell clusters which originated from hormone-treated cells contained about $30 \%$ lower number of cells in comparison to spheroids of the same size initiated from cells before hormonal treatment. Average quantities of cells were $94 \pm 32$ cells vs $154 \pm 54$ cells for 2 -day spheroids derived from hormone-treated and non-treated cells, respectively.

Once established, the growth rate of spheroids from non-treated cells was significantly higher than that of MCF7 cell clusters originated from E2-treated cells (Figure 2E). As seen, during the second day in culture, the mean size of non-treated spheroid populations increased by $23 \%$, while E2-treated clusters increased by only $13 \%$. Overall, the rate of size increase during 3 days in culture was almost three times higher in cancer spheroids grown in the absence of E2 than in clusters cultured in E2supplemented medium. The corresponding doubling time of the cluster cells were $31 \mathrm{~h}$ and $23 \mathrm{~h}$ for hormone-treated and non-treated 3D structures, respectively. Hence, the E2treated spheroid phenotype displays bigger cell size and proliferates at a slower rate.

In addition, the multicellular structures derived from E2-treated and non-treated cells were morphologically different. Two-day MCF7 spheroids exhibited round and smooth shapes, while spheroids established from E2treated cells were less spherical and had rough texture. The average sphericity factor (which describes the roundness of a particle by using central moments) of MCF7 nontreated spheroids was significantly higher than that of spheroids originated from E2-treated cells $(0.81 \pm 0.11$ and $0.62 \pm 0.16, \mathrm{p}<0.005$, respectively). Concurrently, the average parameters that define spheroid smoothness or granularity (entropy, Standard Deviation (SD) and range of gray values) were all significantly higher (1.18 \pm 0.6 , $150.9 \pm 120.5,578.4 \pm 451$, respectively) for the E2-treated spheroids than for the non-treated $(0.7 \pm 0.4,67.1 \pm 37.7$, $259.8 \pm 146.2$, respectively) ( $\mathrm{p}<0.005$ for all parameters). 

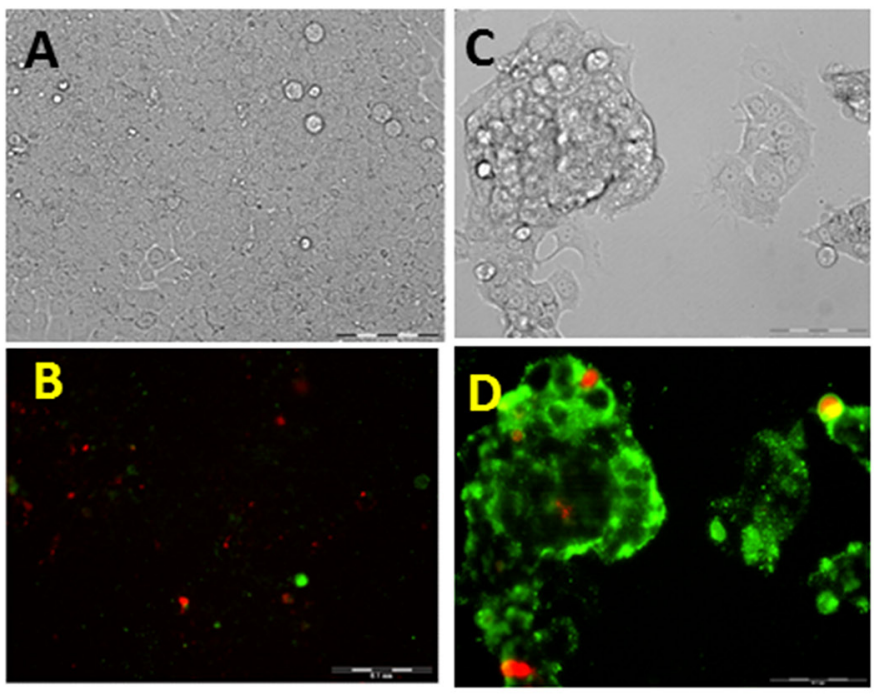

E
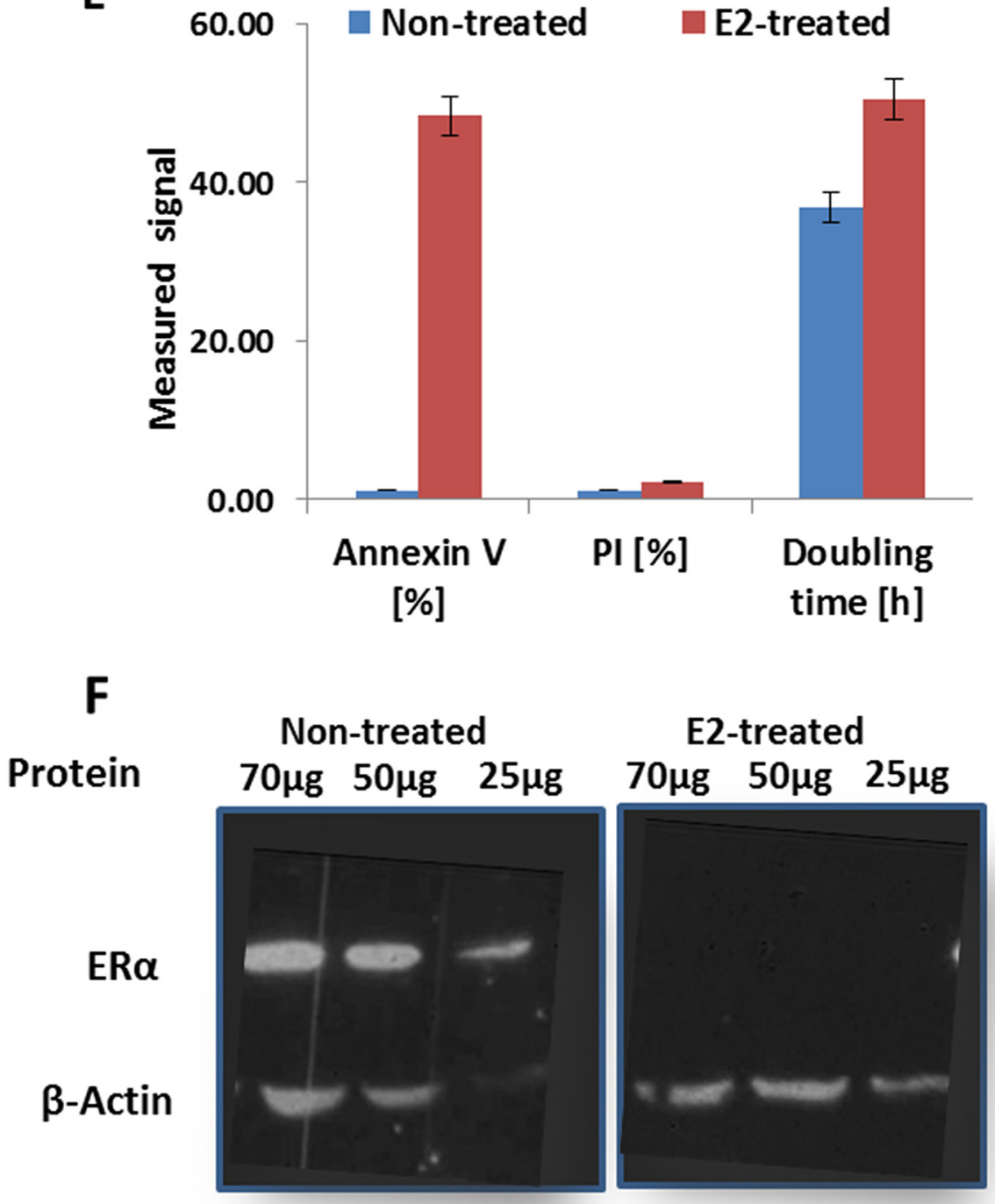

Figure 1: Bright field $(\mathbf{A}, \mathbf{B})$ and corresponding fluorescence images (C,D) of MCF7 cells vulnerable to E2-induced apoptosis before $(A, C)$ and two weeks after hormonal treatment (B,D). Cells were double stained with Annexin V-FITC (green signal) and PI (red signal). (E) Level of apoptosis and doubling time in MCF7 cells before and after exposure to E2. (F) Relative expression levels of ER in non-treated (left) and E2-treated (right) MCF7 cells. 


\section{Effect of NO on spheroid growth}

For analysis of the effect of exogenous NO on MCF7 BC clusters, 2-day spheroids were exposed to NO releasing compound at different concentrations for $24 \mathrm{~h}$. The same cell clusters were monitored before, during and after NO exposure and the ratio between spheroid sectional area before and after treatment, which reflected the change in spheroid size during treatment, was calculated and expressed as growth ratio (GR).

The dose response curve for DiethylenetriamineNONOate (DETA/NO) effect on spheroid growth is depicted in Figure 3. Without hormonal treatment, significant alterations in growth rates were evident when spheroids were incubated for $24 \mathrm{~h}$ with the NO mimetic, DETA/NO, at both low and high concentrations (Figure 3A).

A bimodal response is evident; low doses of DETA/ NO (up to $1 \mu \mathrm{M}$ ) induced a significant increase in growth rate, while in the presence of higher concentrations of NO donor, the GR considerably decreased. The average increase in spheroid area for control spheroid population was $23.7 \pm 0.9 \%$ and for $1 \mu \mathrm{M}$ DETA/NO-treated spheroids $27.8 \pm 0.9 \%$, while an $8.68 \pm 0.1 \%$ decrease in spheroid size was evident upon treatment with $100 \mu \mathrm{M}$ DETA/NO (p $<0.0005$ in both cases). Conversely, no significant change in the size of MCF7 spheroids derived from E2-treated cells was apparent upon treatment with low concentration

A

Non-treated
MCF7 cells

E2-treated MCF7 cells
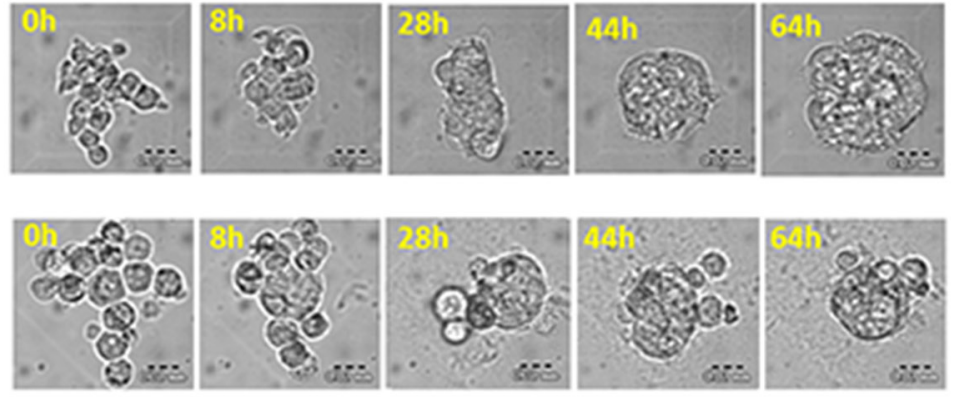

Non-treated

B
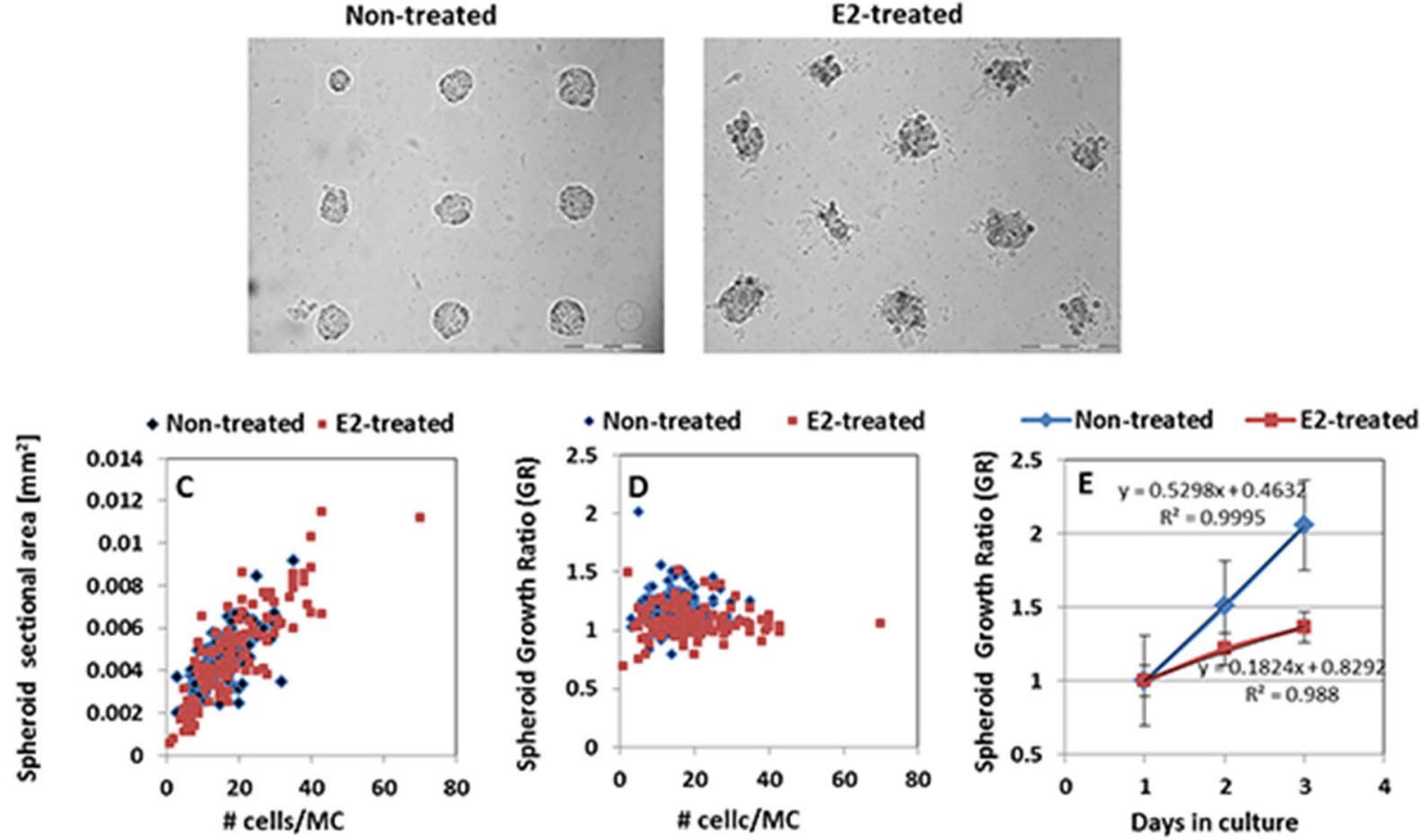

Figure 2: Generation and culturing of 3D multicellular MCF7 BC spheroids within HMC. (A) kinetics of spheroid formation process from non-treated MCF7 cells (upper panel) and E2-treated (lower panel) cells. Cells were seeded within representative MCs in $\mathrm{HMC}$ and allowed to generate multicellular structures. Scale bar $=20 \mu \mathrm{m}$. (B) Bright field images of representative 2-day BC spheroids generated within HMC array from non-treated and E2-treated MCF7 cells. Scale bar $=200 \mu \mathrm{m}$. (C) Correlation between number of cells per microchamber and sectional area of spheroids at day 2. (D) Correlation between number of cells per microchamber and the growth rate of the corresponding spheroids. Each dot represents an individual spheroid. (E) Growth curves of MCF7 spheroid phenotypes within HMC array. Results represent mean $\pm \mathrm{SD}(\mathrm{N}=150)$. 
of NO donor and a small, but significant reduction in the average dimensions was observed following exposure to higher concentrations of DETA/NO (Figure 3A).

Distribution histograms of the GR values measured in individual spheroids generated from E2-treated and non-treated MCF7 cells are shown in Figure 3B,3C. Upon exposure of non-treated $3 \mathrm{D}$ structures to $1 \mu \mathrm{M}$ DETA/NO, a subgroup of spheroids which showed higher relative growth rates was exposed, while with exposure of the same non-treated 3D structures to $100 \mu \mathrm{M}$ DETA/ NO, a slow-growing subgroup presented. When choosing GR values of 1.43 and 1.03 as the higher and lower cutoff levels respectively (mean $\pm \mathrm{SD}$ of the control cell population, $n=400$ spheroids), $31 \%$ of the MCF7 spheroids incubated in the presence of exogenous $\mathrm{NO}$ at $1 \mathrm{nM}$ concentration, displayed a significant increase in size and were labeled "high-proliferating (HP) group" (Figure 3B). Additionally, a decrease in spheroid size, induced by higher NO levels was evident in a group that comprised about $35 \%$ of the spheroid population, and labeled "low-proliferating (LP) group" (Figure 3B). The average GR value of the HP subpopulation was $1.59 \pm 0.18$, while that of the LP subpopulation was $0.97 \pm 0.09$. The parallel changes in mean cell number per spheroid in this phenotype were a twofold increase in HP subgroup (from $116 \pm 33.1$ to $232 \pm 45.1$ cells) and a $7 \%$ decrease in cell number for the LP group (from $122 \pm 29.3$ to $114 \pm 25$ cells), indicating an augmented propagation for the HP clusters and a cessation in cell proliferation with shrinkage of the LP spheroid subpopulation.

It should be noted that no correlation was found between the initial spheroid size and the rate of its growth in the presence or in the absence of DETA/NO. Pearson correlation of individual spheroid size and GR was: $0.042,-0.24363$ and -0.19028 for control, 100 and $1 \mu \mathrm{M}$ DETA/NO, respectively. However, the HP group which appeared following $24 \mathrm{~h}$ incubation in the presence of low NO concentration, is characterized by a significantly small sectional area at $\mathrm{t}=0$ (about $25 \%$ less), which may indicate that the small dimension of these spheroids facilitates rapid diffusion and the action of NO gas molecules.

Conversely, in MCF7 clusters generated from cells exposed to E2, no specific spheroid classes were manifest upon treatment either with low or with higher DETA/NO concentrations (Figure 3C).

\section{Effect of NO on apoptosis level and metabolic state}

For the assessment of metabolic state and apoptosis level, both types of spheroids were double-stained with tetramethylrhodamine methyl ester perchlorate (TMRM) and Annexin V respectively. Representative 3-day MCF7 spheroids derived from non-treated and E2-treated cells following vital staining with TMRM and Annexin $\mathrm{V}$ are shown in Figure 4A. As seen, in the absence of E2, Annexin V staining is almost negligible, while homogeneous high intensity TMRM staining is evident. However, 3D structures exhibited high signals of Annexin $\mathrm{V}$ probe and lower scattered TMRM signals following hormonal exposure.

As expected, Annexin V results showed a high level of early apoptosis in MCF7 spheroids exposed to E2. The proportion of Annexin V-positive spheroids and averaged area fraction of the fluorescent signal are significantly higher in this spheroid population (Figure 4B).

TMRM, which accumulates within mitochondria in inverse proportion to $\Delta \psi_{\mathrm{m}}$, is utilized for comparative mitochondrial membrane potential evaluations of the $3 \mathrm{D}$ multicellular structures (see Supplementary Material 2). Both TMRM fluorescence parameters, the TMRM CV and TMRM Ratio (see Materials and Methods), were
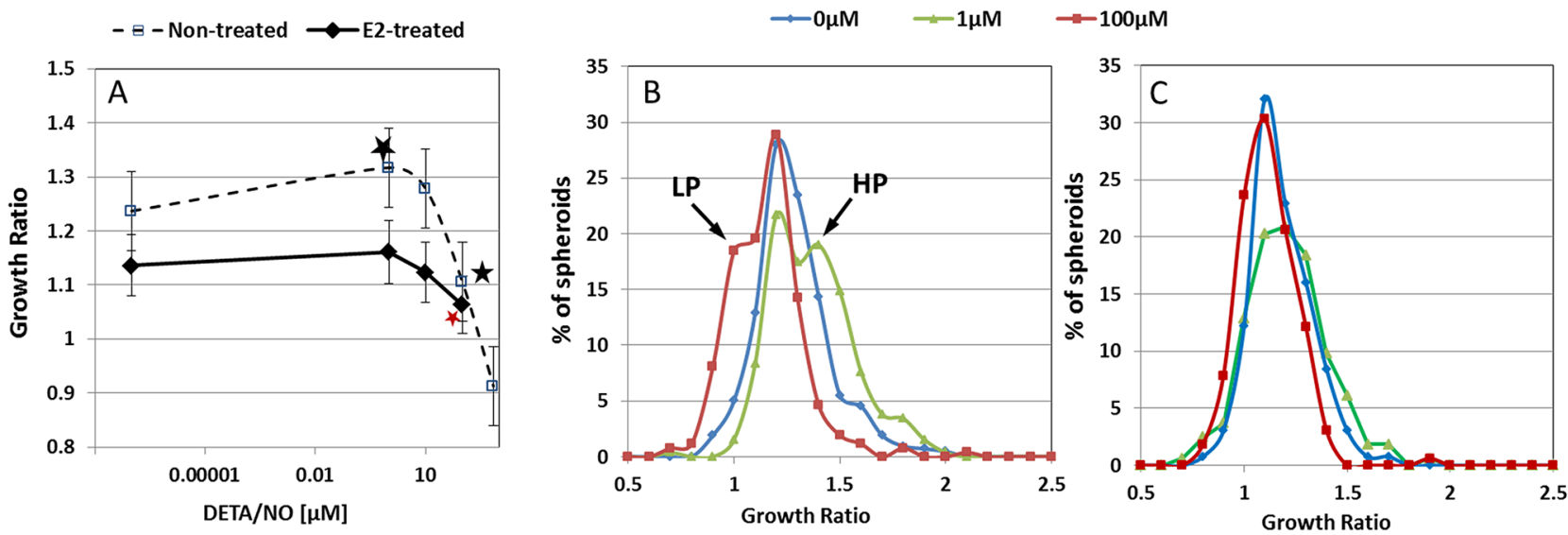

Figure 3: The effect of NO on spheroid growth. (A) Dose response curve of the impact of DETA/NO on spheroid growth. Asterisks represent statistically significant differences from $0 \mu \mathrm{M}$ NO donor. Distribution histograms of MCF7 spheroid GR before (B) and after E2 treatment $(\mathbf{C})$ upon incubation with DETA/NO at $1 \mu \mathrm{M}$ and $100 \mu \mathrm{M}$. Arrows represent high (HP) and low (LP) proliferating subgroups, correspondingly. 
significantly different in MCF7 spheroids that originated from cells deprived of or exposed to E2 (Figure 4C). While lower TMRM CV and high TMRM Ratio (suggesting relatively high mitochondrial membrane potential and high metabolic activity) characterized MCF7 spheroids grown in the absence of hormone, BC spheroids that were cultured in the presence of E2 showed significantly low TMRM Ratio and higher spatial distribution of the fluorescent signals, reflecting lower metabolic activity. The mean TMRM Ratio was $1.72 \pm 0.61$ and $0.99 \pm 0.38 \mathrm{au}$, $\mathrm{p}<0.00005$, for MCF7 spheroid populations grown in the absence and in the presence of E2, respectively. The mean TMRM CV values for the same spheroid groups were $0.59 \pm 0.13$ and $0.78 \pm 0.27 \mathrm{au}, \mathrm{p}<0.00005$, respectively.

The decrease in mitochondrial membrane potential accompanied enhanced cytochrome c release (Figure 4D) as well as elevated caspase-3 activity (Figure 4E, $4 \mathrm{~F}$ ), confirming that mitochondrial apoptotic pathway is induced by hormonal treatment. BC spheroids of both phenotypes were grown, permeabilized and then fixed within the HMA and stained by anti-cytochrome c Ab. Upon exposure to E2, apoptotic cells which have released their cytochrome $\mathrm{c}$ from the mitochondria to the cytoplasm, demonstrated significantly reduced staining intensity (see Materials and Methods). Average cytochrome c Fluorescence Intensity (FI) was 8.64 $\pm 1.4 \mathrm{au}$ and 5.7 $\pm 0.7 \mathrm{au} \mathrm{p}<1.2^{*} 10^{10}$, in estrogen-deprived and E2exposed spheroid populations, respectively (Figure 4D).

Similar decrease in mitochondrial membrane potential and enhanced cytochrome c release was also observed in ER-positive BC cell line (MCF7:5C) resistant to long-term estrogen deprivation that underwent programmed cell death in the presence of physiologic concentrations of E2 [20].

The activity of caspase-3, a critical executioner enzyme of apoptosis in the caspase cascade, was determined in individual live spheroids, using a bifunctional caspase-3 substrate which consists of a fluorogenic DNA dye and a DEVD moiety. This probe detects real time caspase-3 activity in intact cells. Figure 4E displays caspase- 3 activities measured within representative intact hormone-deprived and hormonetreated BC spheroids. While the non-treated BC spheroid population is characterized by low enzyme activity, more than $60 \%$ of the E2-treated spheroid population exhibit increased caspase-3 activity. Mean FI signal was $10.05 \pm 11.1 \mathrm{au}$ and $1.97 \pm 1.18 \mathrm{au}$, for E2-treated and E2deprived spheroids, respectively. $\mathrm{p}<0.00018$ (Figure 4F). The area fraction of caspase- 3 activity was respectively significantly higher, following hormonal treatment. (Area
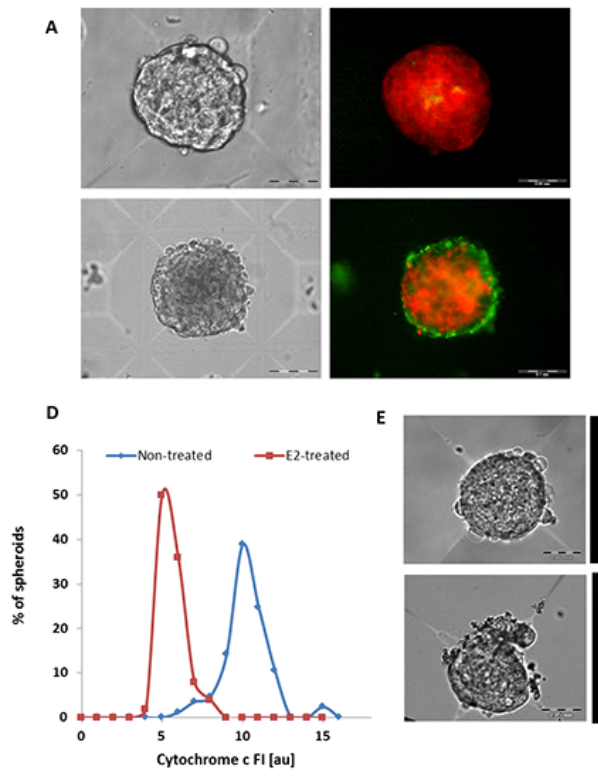
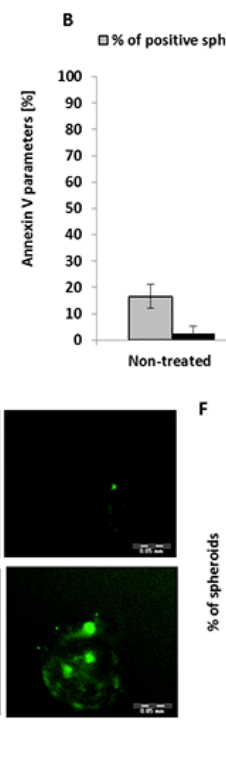

ds -

- Area fraction $[\%]$
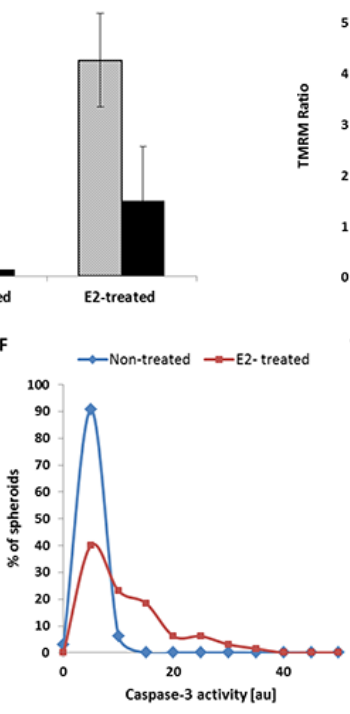

c
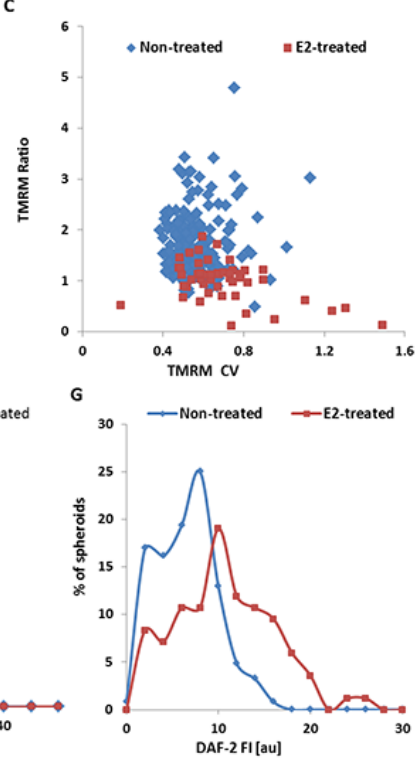

Figure 4: Metabolic activity and apoptosis of MCF7 spheroids in HMC array. (A) Representative 3-day spheroids derived from non-treated (upper panel) and E2-treated cells (lower panel), stained for TMRM and Annexin V. Bright field (left panel) and overlapped fluorescent image of TMRM and Annexin V (right panel). Bars represent $100 \mu \mathrm{m}$ and $50 \mu \mathrm{m}$ for upper and lower panels, respectively. Annexin V (B) and TMRM fluorescence parameters (C) measured in populations of 3D structures generated from E2-treated and nontreated cells. (D) Distribution histograms of cytochrome C level reflected by anti-cytochrome C FI, measured in individual hormonedeprived and hormone-treated MCF7 spheroid populations. Note that when cytochrome $\mathrm{c}$ is translocating from the mitochondria to the cytosol during apoptosis process, the mean FI of cytochrome c signal is decreased. (E) Representative 3-day spheroids derived from nontreated (upper panel) and E2-treated (lower panel) cells, vitally stained for caspase-3 activity using NucView ${ }^{\mathrm{TM}} 488$. Bright field (left panel) and fluorescent image of enzyme activity (right panel). Bars represent 50 $\mu \mathrm{m}$. (F) Distribution histograms of caspase-3 activity measured in individual MCF7 3D structures generated from non-treated and hormone-treated cells. (G) Distribution histograms of relative intracellular NO levels as reflected by DAF-2 FI measured in individual hormone-deprived and hormone-treated BC spheroid populations. 
fraction of $3.97 \pm 6.18 \%$ and $24 \pm 24.18$ in E2-deprived and E2-treated spheroids, respectively. $\mathrm{p}<0.000004$ ).

The involvement of reactive oxygen and nitrogen species (ROS/RNS) in mitochondria-mediated apoptosis pathways has been widely described [21].

Endogenous NO levels in BC spheroids were measured by vital staining with 4,5-diaminofluorescein diacetate (DAF-2DA) probe, which estimates the relative NO content in cells and spheroids (see Supplementary Material 3). Upon probe loading, the ester bonds of DAF2DA are hydrolyzed by intracellular esterases, generating DAF-2, which accumulates within the cell, and becomes fluorescent upon oxidation by NO. A significant difference was found in the basal NO content of the two spheroid phenotypes. In E2-treated spheroids which underwent extensive apoptosis, the basal NO content was higher than in hormone deprived clusters (Figure 4F). Average DAF-2 FI was $5.55 \pm 3.21$ au and $9.65 \pm 5.23$ au $\mathrm{p}<6.2^{*} 10^{-9}$ in nontreated and E2-treated cell clusters, respectively.

Similar association between elevated NO concentrations and cellular apoptosis was described by others in several tissues including liver [22] and cardiovascular system [23].
The impact of extracellular NO on apoptosis levels of MCF7 3D structures is shown in Figure 5. Incubation with $1 \mu \mathrm{M}$ NO donor did not provoke any alteration in apoptosis levels in 3D structures deprived of hormonal treatment, since no changes were observed, either in Annexin V signal, caspase-3 activity, or in endogenous NO levels (Figure 5A,5C,5E).

However, $100 \mu \mathrm{M}$ DETA/NO induced significant alterations; $79 \%$ of the MCF7 clusters became Annexin $\mathrm{V}$-positive and the average area fraction of the fluorescent signal increased to $10 \%$ (Figure $5 \mathrm{~A}$ ). Concomitantly, exposure to $100 \mu \mathrm{M} \mathrm{NO}$ donor significantly augmented intracellular caspase-3 activity (Figure 5C) and cytochrome $\mathrm{c}$ release, indicating a mitochondrial apoptotic pathway mediated by higher concentrations of NO.

Interestingly, exposure to DETA/NO significantly attenuated E2-dependent phosphatidylserine (PS) externalization in MCF7 spheroids at both donor concentrations. Almost all spheroids cultured in the presence of E2 were Annexin V-positive and showed high variability in the probe FI levels (Figure 5B). NO-donor at $1 \mu \mathrm{M}$ and $100 \mu \mathrm{M}$ decreased the average area fraction of Annexin V signal by $49.3 \%$ and $58.5 \%$ respectively.
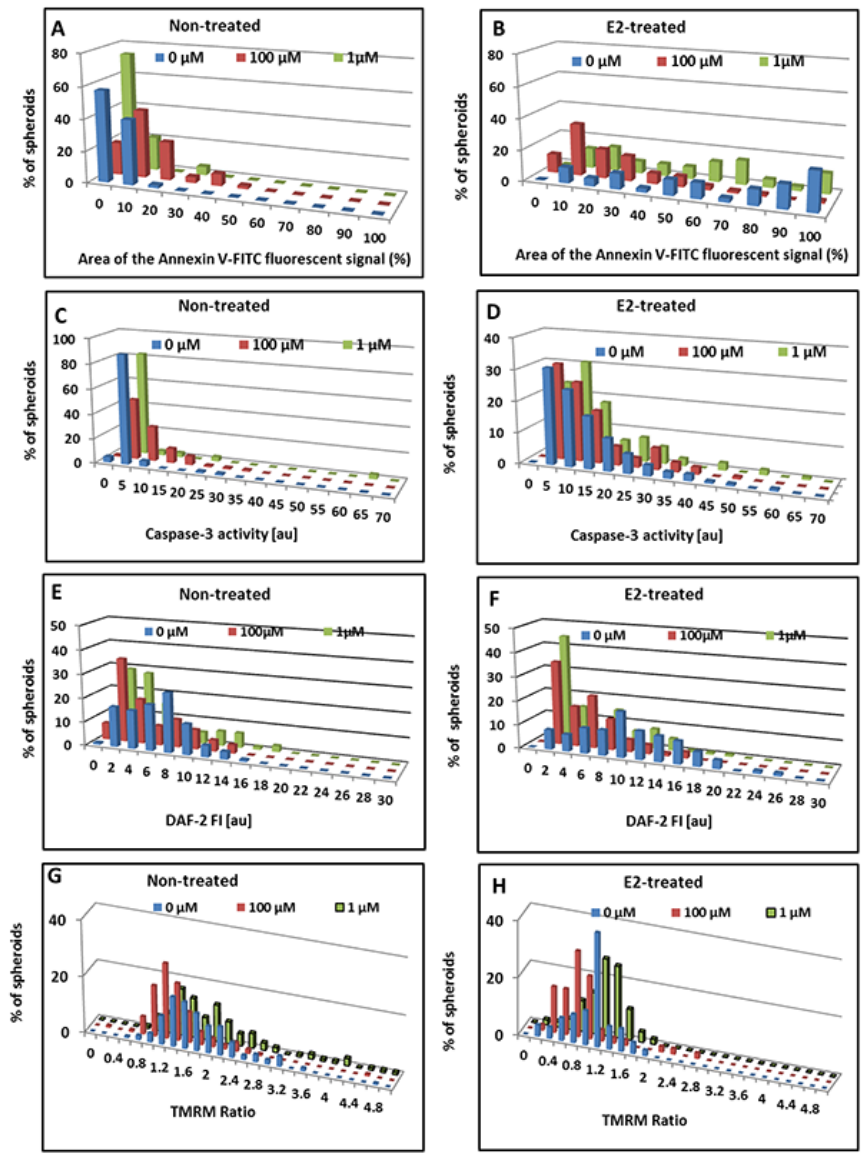

Figure 5: Effect of exogenous NO on apoptotic parameters of MCF7 BC spheroids. Distribution histograms of Annexin V fractional area $(\mathbf{A}, \mathbf{B})$ caspase-3 activity $(\mathbf{C}, \mathbf{D})$, relative DAF-2 FI $(\mathbf{E}, \mathbf{F})$ and TMRM Ratio $(\mathbf{G}, \mathbf{H})$ in individual MCF7 3D structures upon 24h incubation with DETA/NO. A,C,E,G - spheroids generated from hormone-deprived cells. B,D,F,H - those derived from E2-treated spheroids. 
The average area fraction of Annexin V-FITC fluorescent signal was $55.8 \pm 25.0 \%, 28.3 \pm 24.7 \%$ and $23.2 \pm 17.9 \%$ for control, $1 \mu \mathrm{M}$ and $100 \mu \mathrm{M}$ DETA/NO, respectively, $\mathrm{p}<0.0005$ for both concentrations. Concomitantly, the amount of dead cells, as reflected by the area fraction of PI FI in these hormone-treated spheroids, decreased from $5.01 \pm 5.5 \%$ to $2.6 \pm 3.8 \%(\mathrm{p}=0.004)$ upon $24 \mathrm{~h}$ exposure to $1 \mu \mathrm{M}$ NO donor.

In addition to the decrease in PS externalization, $24 \mathrm{~h}$ exposure of hormone-treated spheroids to DETA/NO at both concentrations resulted in significant reduction of endogenous NO levels (Figure 5F). Average DAF-2 FI in this phenotype decreased by $50 \%$.

However, neither cytochrome $\mathrm{c}$ translocation from mitochondria to cytoplasm, nor the high enzymatic activity of caspase-3 which characterizes spheroids derived from E2-treated MCF7 cells, were affected following 24h exposure to NO donor at both concentrations. (Figure 5D), demonstrating that this mitochondrial cell death pathway was not inhibited.

As mentioned above, basic metabolic activity of 3D structures is significantly different in MCF7 spheroid phenotypes that were generated from cells exposed to E2, than of those generated from non-treated cells. The influence of exogenous $\mathrm{NO}$ on mitochondrial membrane potential in the two types of BC spheroids is depicted in Figure $5 \mathrm{G}, 5 \mathrm{H}$. In accordance with the impact of $\mathrm{NO}$ on spheroid growth, a dual effect of NO on 3D structures deprived of hormonal treatment is evident. Exposure to $1 \mu \mathrm{M}$ NO donor enhanced mitochondrial activity (average TMRM Ratio increased from $1.7 \pm 0.4 \mathrm{au}$ to $2.1 \pm 0.6 \mathrm{au}$, $\mathrm{p}<0.0005$ ) while $100 \mu \mathrm{M}$ NO donor reduced mitochondrial membrane potential (TMRM Ratio $1.3 \pm 0.3 \mathrm{au}, \mathrm{p}<0005$ ) (Figure 5E) concomitantly with the increase in Annexin $\mathrm{V}$ signal (Figure 5A), and enhanced caspase-3 activity (Figure 5C).

For E2-treated spheroid phenotype, which exhibited low metabolic activity, $24 \mathrm{~h}$ incubation with $1 \mu \mathrm{M}$ NO donor slightly increased TMRM staining, and $100 \mu \mathrm{M}$ DETA/NO further reduced mitochondrial membrane potential (Figure 5F). Average TMRM Ratio values were $0.99 \pm 0.34 \mathrm{au}, 1.09 \pm 0.33 \mathrm{au}$, and $0.78 \pm 0.49 \mathrm{au}, \mathrm{p}=0.01$ for spheroids incubated without and with the presence of $1 \mu \mathrm{M}$ and $100 \mu \mathrm{M}$ DETA/NO, respectively.

Expression of the inhibitor of apoptosis (IAP) protein survivin, in tumors, correlates with inhibition of apoptosis, decreased rate of cell death, aggressiveness and resistance to chemotherapy [24]. In order to investigate the association between this IAP protein and NO effects, intracellular levels of survivin were analyzed by immunofluorescent staining. Two-day BC spheroids treated with hormones were exposed to DETA/NO for $24 \mathrm{~h}$ and then fixed within the HMC array and stained by antisurvivin Abs. High immunoreactivity of survivin protein was detected in the cytoplasm of the MCF7 spheroids (Figure 6A). Apoptosis suppression of hormone-treated
BC spheroids by NO involved modulation of survivin expression, since low doses of NO donor augmented the intracellular levels of the IAP protein (Figure 6B). Mean FI and the area fraction of survivin signal were both significantly elevated in E2-treated spheroids that were exposed to $1 \mu \mathrm{M}$ DETA/NO. Conversely, survivin levels were down-regulated in E2-treated spheroids that were exposed to $100 \mu \mathrm{M}$ DETA/NO (Figure 6B). Average survivin FI in E2-treated spheroid population was $8.05 \pm$ 1.3au, $12.1 \pm 1.7 \mathrm{au}$, and $6.9 \pm 1.2 \mathrm{au}$, before and after incubation with $1 \mu \mathrm{M}$ and $100 \mu \mathrm{M}$ NO donor, respectively, $\mathrm{p}<4.5^{*} 10^{5}$ for both concentrations.

Overexpression of survivin was shown to be associated with inhibition of cell death initiated either through the extrinsic or the intrinsic apoptotic pathways [25]. It has been shown that survivin and other IAPs can directly or indirectly inhibit caspases or pro-caspases, respectively [26].

Intriguingly, in $\mathrm{BC}$ spheroids that undergo estrogeninduced apoptosis, NO-induced upregulation of survivin was not associated with a decrease in caspase- 3 activity. This may indicate that under the experimental conditions used here, during the $24 \mathrm{~h}$ exposure of $3 \mathrm{D}$ structures to low doses of NO donor, the anti-apoptotic pathway had already been activated, but the enzymatic activity of the cell death protease had not yet been significantly interrupted.

\section{Effect of NO on ER expression levels in MCF7 spheroids}

In agreement with the results shown in 2D culture, ER was downregulated both at the mRNA and protein levels in spheroids generated from hormonetreated MCF7 cells. Upon exposure to estrogen, the 3D structures expressed low mRNA levels (Figure 7A, 7B, $0 \mu \mathrm{M})$, undetectable ER protein as measured by western blotting (Figure 7C,0 $0 \mu \mathrm{M}$ ), and significantly altered fluorescent signals by immunostaining (Figure 7D). Relative mRNA levels decreased from $0.37 \pm 0.03$ au to $0.11 \pm 0.10 \mathrm{au}, \mathrm{p}<0.0008$, following hormonal treatment (Figure 7B).

The immunofluorescent staining of $\mathrm{ER} \alpha$ in two representative $3 \mathrm{D}$ structures is shown in Figure 7E (left panel). Green fluorescence was not restricted to the nucleus, but was rather scattered throughout the cytoplasm and on cell borders. Hence, ER seems to redistribute from the nucleus into extranuclear sites. In those experiments where the primary anti-ER $\alpha$ antibody was omitted, there was no green staining at all, indicating that the green fluorescence shown in Figure 7E is specific staining of ER $\alpha$. Using a cutoff value for ER-positive spheroids as the mean $\mathrm{FI} \pm \mathrm{SD}$ of control spheroid population $(n=100$, without primary $\mathrm{Ab}$, see Materials and Methods for ER immunostaining and image analysis), revealed that ER fluorescent signal was lower in E2-treated BC spheroids. While prior to hormonal treatment, the whole MCF7 spheroid population was ER- 
positive, after E2 treatment, about $82 \%$ of the spheroid population was found to be ER-positive. Moreover, the FI and the area fraction of ER fluorescent signal were both significantly lower after hormonal treatment (Figure 7D). The averaged area fraction of the fluorescent signal decreased from $44.5 \pm 23.4 \%$ to $5.8 \pm 10.4 \%$ and the mean FI from $6.5 \pm 1.4$ au to $3.5 \pm 1.9$ au, for cell clusters derived from non-treated and E2-treated cells, respectively, $\mathrm{p}<0.0005$ for both cases.

48h BC spheroids generated from E2-treated and non-treated MCF7 cells were exposed to DETA/NO for $24 \mathrm{~h}$ and then either fixed within the HMC array and
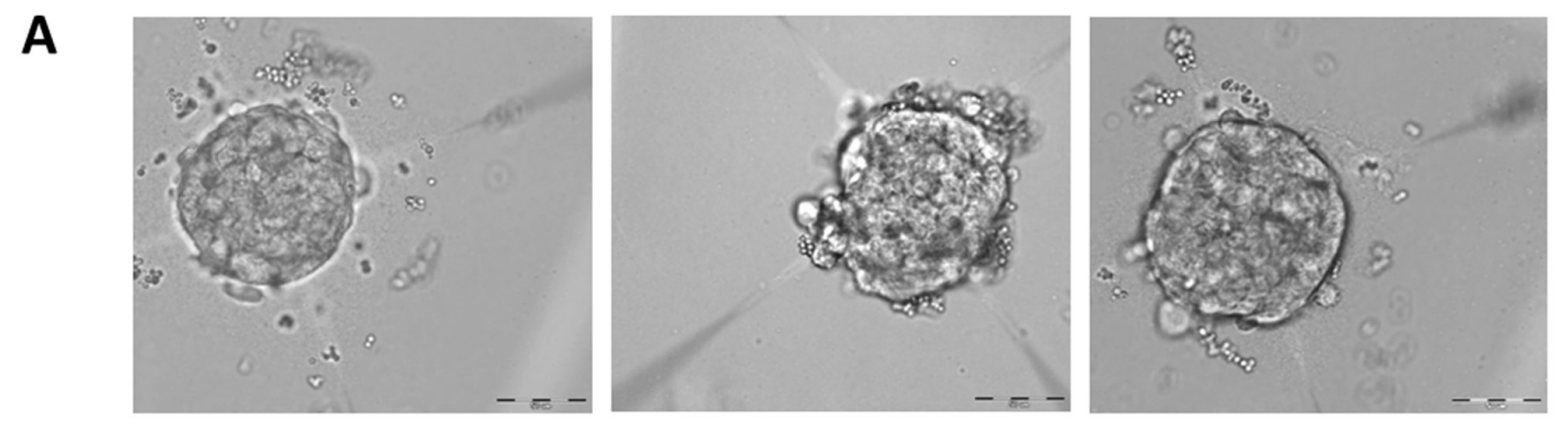

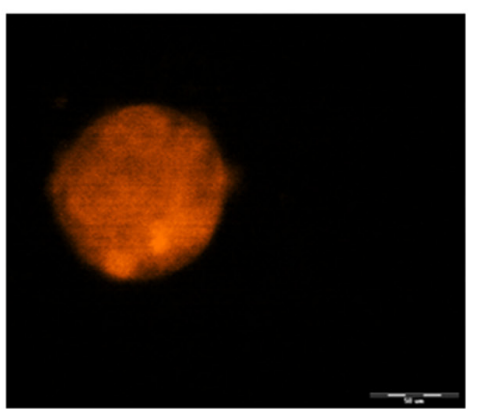

0 DETA/NO

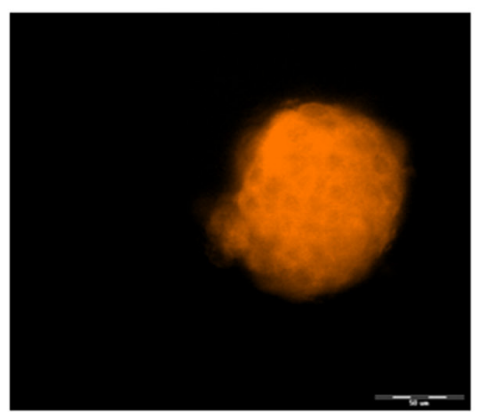

1 $\mu \mathrm{M}$ DETA/NO

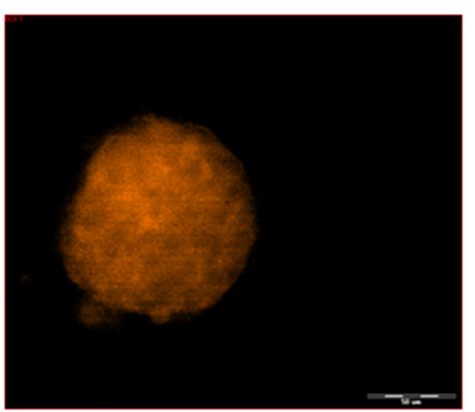

$100 \mu \mathrm{M}$ DETA/NO

B

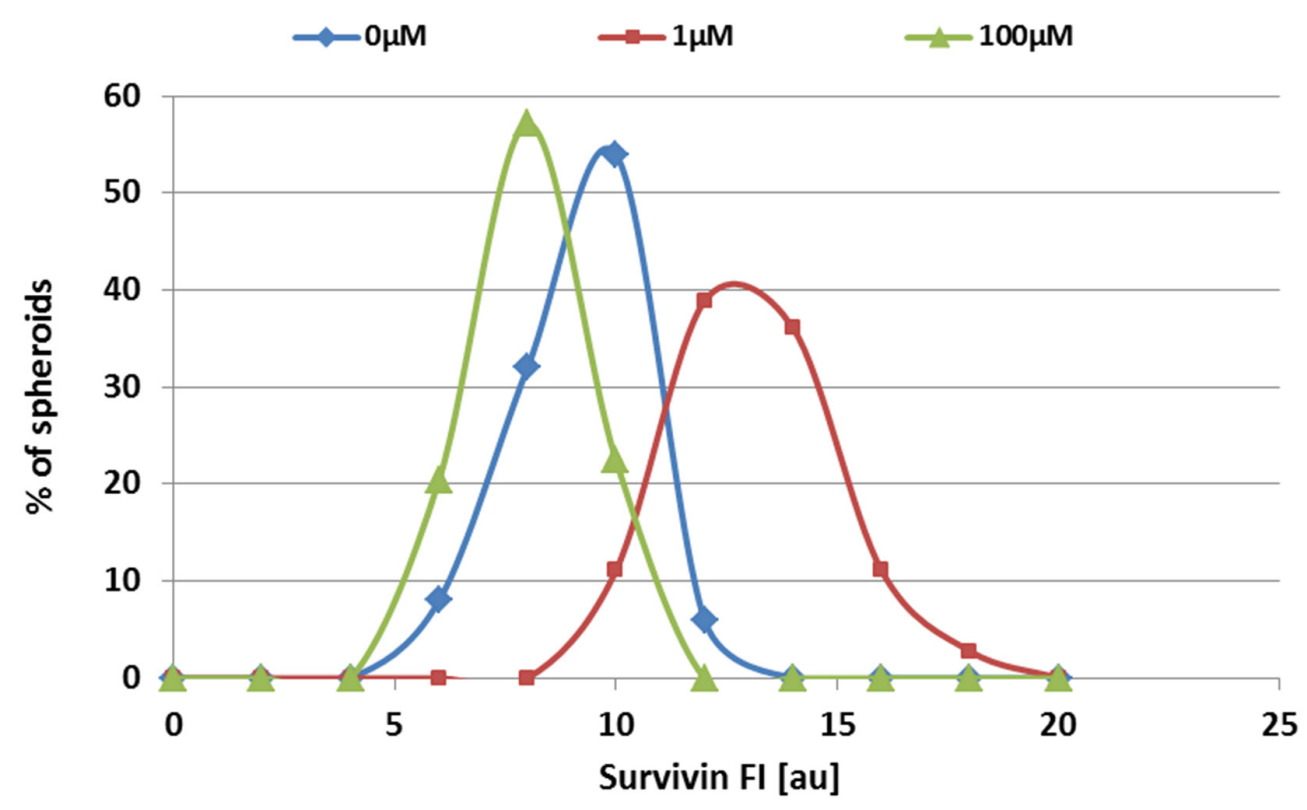

Figure 6: Expression levels of survivin in hormone treated BC spheroids. (A) Bright field (upper panel) and corresponding fluorescence images (lower panel) of representative E2-treated spheroids upon $24 \mathrm{~h}$ exposure to $1 \mu \mathrm{M}$ and $100 \mu \mathrm{M}$ NO donor, following fixation and immune-staining for survivin. Scale bar $=50 \mu \mathrm{m}$. (B) Distribution histograms of survivin expression levels in E2-treated individual 3D structures upon $24 \mathrm{~h}$ incubation with DETA/NO. 
stained by anti-ER $\alpha$ Abs for imaging-based analysis or recovered from the array, pooled and analyzed using reverse transcription polymerase chain reaction (RT-PCR) and western blotting.

ER levels in 3D structures derived from nontreated MCF7 cells were significantly downregulated upon exposure to $1 \mu \mathrm{M}$ NO donor, as measured either by averaging protein content using western blot analysis (Figure 7C) or by image analysis at the resolution of individual spheroids (Figure 8A, 8B). As indicated by western blot, a significant decrease in the relative ER protein level from $1.43 \pm 0.02 \mathrm{au}$ to $0.54 \pm 0.15 \mathrm{au}$ was evident after $24 \mathrm{~h}$ incubation with $1 \mu \mathrm{M}$ DETA/NO, $\mathrm{p}=0.027$, but no change was observed in the presence of $100 \mu \mathrm{M}$ DETA/NO (relative protein level 1.56 $\pm 0.19 \mathrm{au}$ $\mathrm{p}>0.05)$.

RT-PCR analysis indicated that the downregulation of ER expression level is post-translational, since ER mRNA did not change upon incubation with NO donor (Figure 7A, 7B).

Similar results were obtained by ER immunostaining (Figure 8A). Both ER fluorescence parameters - spheroid mean FI and the area fraction of the fluorescent signal were significantly lower in BC spheroids treated with $1 \mu \mathrm{M}$ NO donor. The intensity of the fluorescence signal and its area fraction were $6.4 \pm 1.4 \mathrm{au}$ and $44.5 \pm 23.7 \%$ respectively, and decreased to $3.9 \pm 0.9 \mathrm{au}$ and $14.9 \pm 14.3 \%$ following $24 \mathrm{~h}$ incubation in the presence of $1 \mu \mathrm{M}$ DETA/ NO $(p<0.005$, for both parameters). However, exposure to higher concentrations of DETA/NO $(100 \mu \mathrm{M})$ did not induce a significant effect on ER expression level in these cell clusters (Figure 8A).

About $15-20 \%$ of E2-treated spheroids are ER negative. Nevertheless, in contrast to the effect on E2deprived phenotype, $24 \mathrm{~h}$ incubation in the presence of DETA/NO at both concentrations did not induce significant changes on protein levels of the hormone receptor (Figure $8 \mathrm{~B}$ ).

The substantial downregulation of ER induced by low NO concentrations in E2-deprived MCF7 spheroids correlated with the increase in GR parameter (Figure $8 \mathrm{C})$. As seen, the spheroid population that was exposed to $1 \mu \mathrm{M}$ DETA/NO showed a higher proliferation rate and concomitantly exhibited lower receptor levels. Using the K-means algorithm, we were able to cluster the three spheroid sub-groups according to both parameters: GR and ER expression levels. For E2-treated 3D clusters, no such correlation exists (Figure 8D).

Estrogen and progesterone receptors are likely to be lost during hormone therapy [27]. Moreover, the loss of

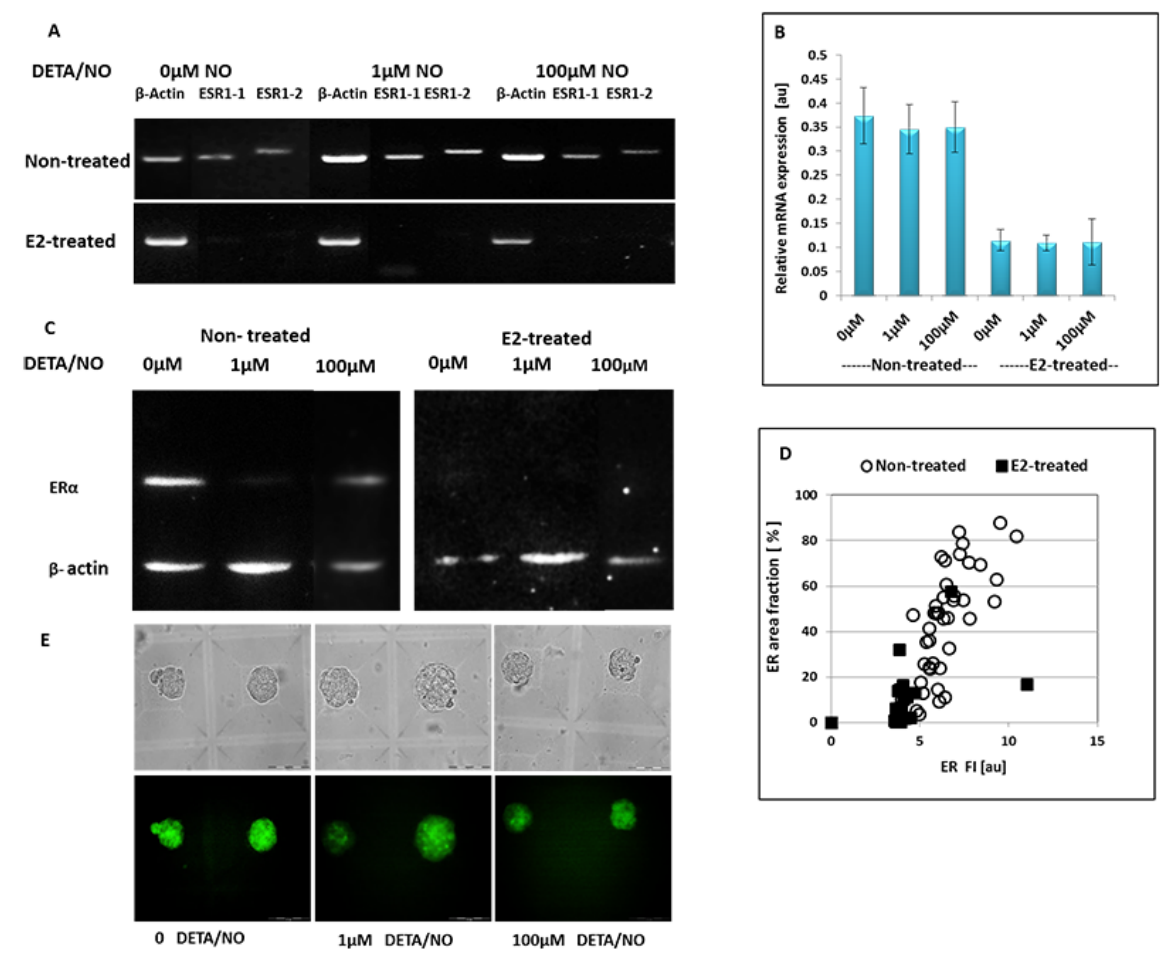

Figure 7: The effect of NO-donor on ER status in hormone-deprived and E2-treated MCF7 spheroids. (A) Gel visualization of the PCR products. (B) Relative mRNA expression levels of ER, calculated as density of the product of ESR1 divided by that of the $\beta$-actin from the same cDNA. Bars represent SE of 3 experiments. (C) Relative protein expression levels of ER protein. (D) Fluorescence parameters of ER staining in individual MCF7 spheroids generated from E2-treated (solid squares) and non-treated cells (hollow circles). (E) Bright field (upper panel) and corresponding fluorescence images (lower panel) of two representative spheroids generated in adjacent MCs before and after $24 \mathrm{~h}$ incubation in the presence of $1 \mu \mathrm{M}$ and $100 \mu \mathrm{M}$ DETA/NO. Scale bar $=100 \mu \mathrm{m}$. 
ER may reflect a mechanism that can result in endocrine resistance [28].

Hence, the substantial downregulation of ER induced by low NO concentrations concomitantly with an increase in GR and in TMRM Ratio, may imply a shift into more aggressive $\mathrm{BC}$ phenotypes.

\section{Effect of NO on spheroid invasion}

It has been shown that low NO flux may stimulate tumor expansion and migration/invasion [29], hence, the possibility that low NO concentrations induce an aggressive invasive phenotype, was tested. MCF7 spheroids were embedded within the extra-cellular matrix (ECM) component and the migration dynamics of each cell-cluster was measured in response to $1 \mu \mathrm{M}$
DETA/NO. Changes in morphology and location of 3D spheroids over $18 \mathrm{~h}$ period of exposure to $\mathrm{NO}$ donor, is shown in Supplementary Videos 3-6 and Figure 9. Upon embedding in collagen, both MCF7 spheroid phenotypes remain spherical cell aggregates with smooth surfaces. In the course of culturing within the collagen matrix, spheroids tend to lose their sphericity (Figure 9A, 9B upper panel). Interestingly, in the presence of $1 \mu \mathrm{M}$ DETA/ NO, hormone-deprived MCF7 BC spheroids dramatically transformed their shape and position (Figure 9A). These spheroid phenotypes become more flat and translocate in the surrounding collagen matrix. Before exposure to $\mathrm{NO}$ donor, the average migration distance in collagen over an $18 \mathrm{~h}$ period, was $78.8 \mu \mathrm{m}(\mathrm{n}=100)$ while in the presence of DETA/NO, MCF7 spheroids exhibited heterogeneous invasion capacity and the average migration distance
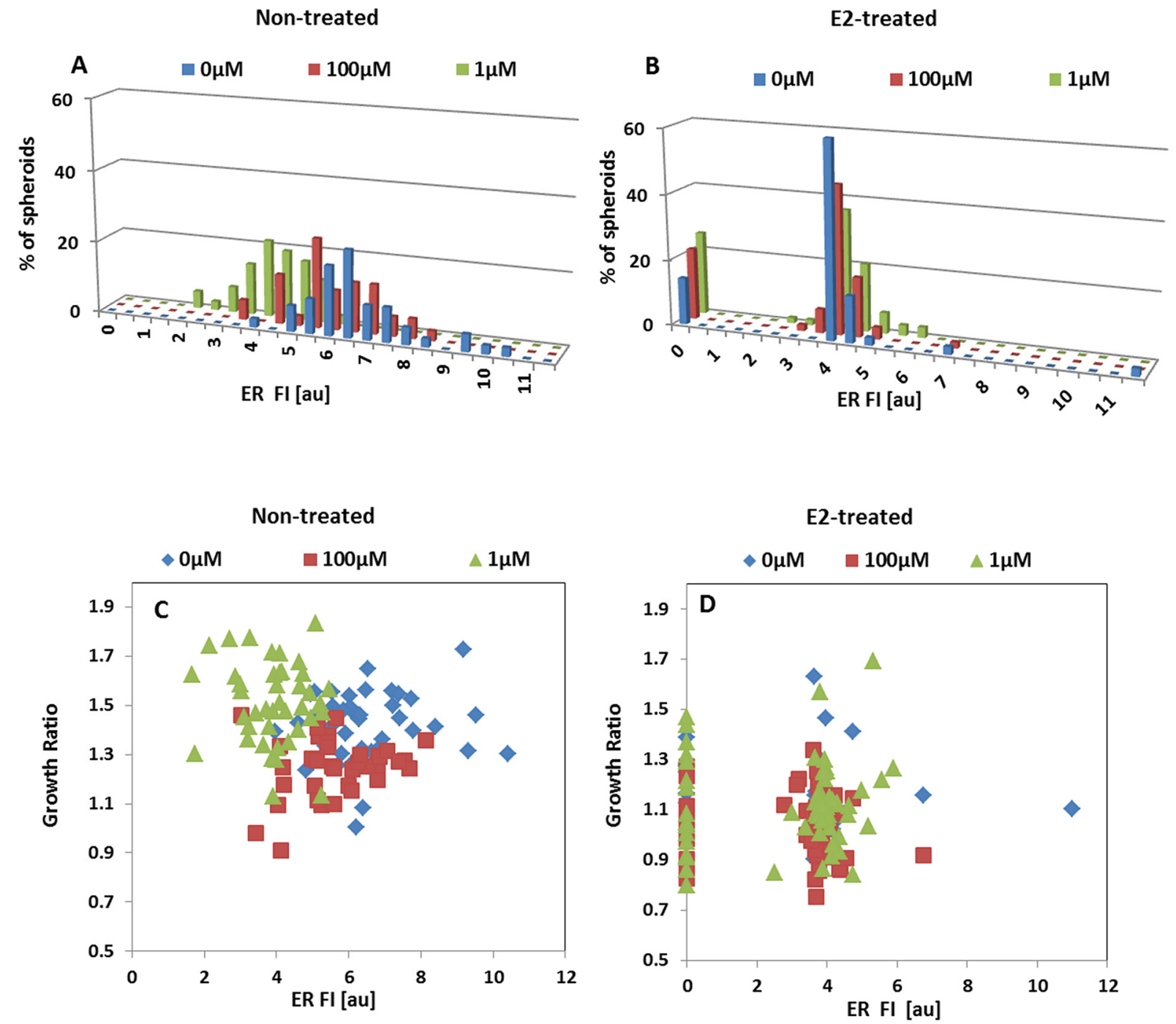

Figure 8: Effect of NO on the relative expression of ER by MCF7 spheroids. Distribution histograms of ER expression levels in individual MCF7 3D structures upon 24h incubation with DETA/NO. (A) Hormone deprived spheroids. (B) E2-treated MCF7 spheroids. Correlation between GR and ER levels in E2-deprived (C) and E2-treated (D) individual spheroids upon exposure to NO-donor. 
was significantly extended $(316.4 \mu \mathrm{m}, \mathrm{p}<0.0005)$ (Figure 9C). Conversely, E2-treated cell clusters, did not move within collagen matrix, and no evidence of collective invasion/migration was found upon exposure to $1 \mu \mathrm{M}$ NO donor (Figure 9B). Migration distance was $43.1 \mu \mathrm{m}$ and $33.2 \mu \mathrm{m}$ in the absence and in the presence of DETA/ NO, respectively $p>0.05$ (Figure 9D). The collective invasion induced by $\mathrm{NO}$ in E2-deprived spheroids was accompanied by over-expression of two cellular proteins; CXCR4 and vimentin. CXCR4, a G protein-coupled cell surface chemokine receptor, was shown to promote BC metastasis to organs [30]. Typical membrane staining is observed upon vital probing of $\mathrm{BC}$ spheroids by anti CXC4R Abs. (Figure 10A). The averaged FI signal of CXCR4 protein in live $\mathrm{BC}$ spheroids increased from $1.98 \pm 2.3$ au to $4.24 \pm 5.0(p<0.0013)$, and the area fraction of the receptor signal increased from $7.8 \pm 7.1$ au, to
$16.4 \pm 18.1, \mathrm{p}<0.0008$, following NO mediated migration (Figure 10B). Concomitantly, the same spheroids which exhibited an invasive phenotype, showed increased vimentin levels (Figure 10C). Averaged vimentin FI signal was $1.82 \pm 0.7$ au and $2.24 \pm 0.76 \mathrm{au},(\mathrm{p}<0.03)$, before and after exposure to NO donor, correspondingly. However, no correlation was found between the cellular expression levels of CXCR4 and vimentin, measured on the same cell clusters (Pearson correlation $=-0.03$ ) .

Overexpression of vimentin, a major constituent of the intermediate filament of proteins, was shown to be correlated with aggressive phenotype and increased invasion of BC cell lines [31]. Furthermore, vimentin was reported to play a major role in the epithelial-tomesenchymal transition (EMT) process of $\mathrm{BCs}$, and its knock-down resulted in a decrease in genes linked with $\mathrm{BC}$ invasion and the basal-like phenotype [32]. Collective
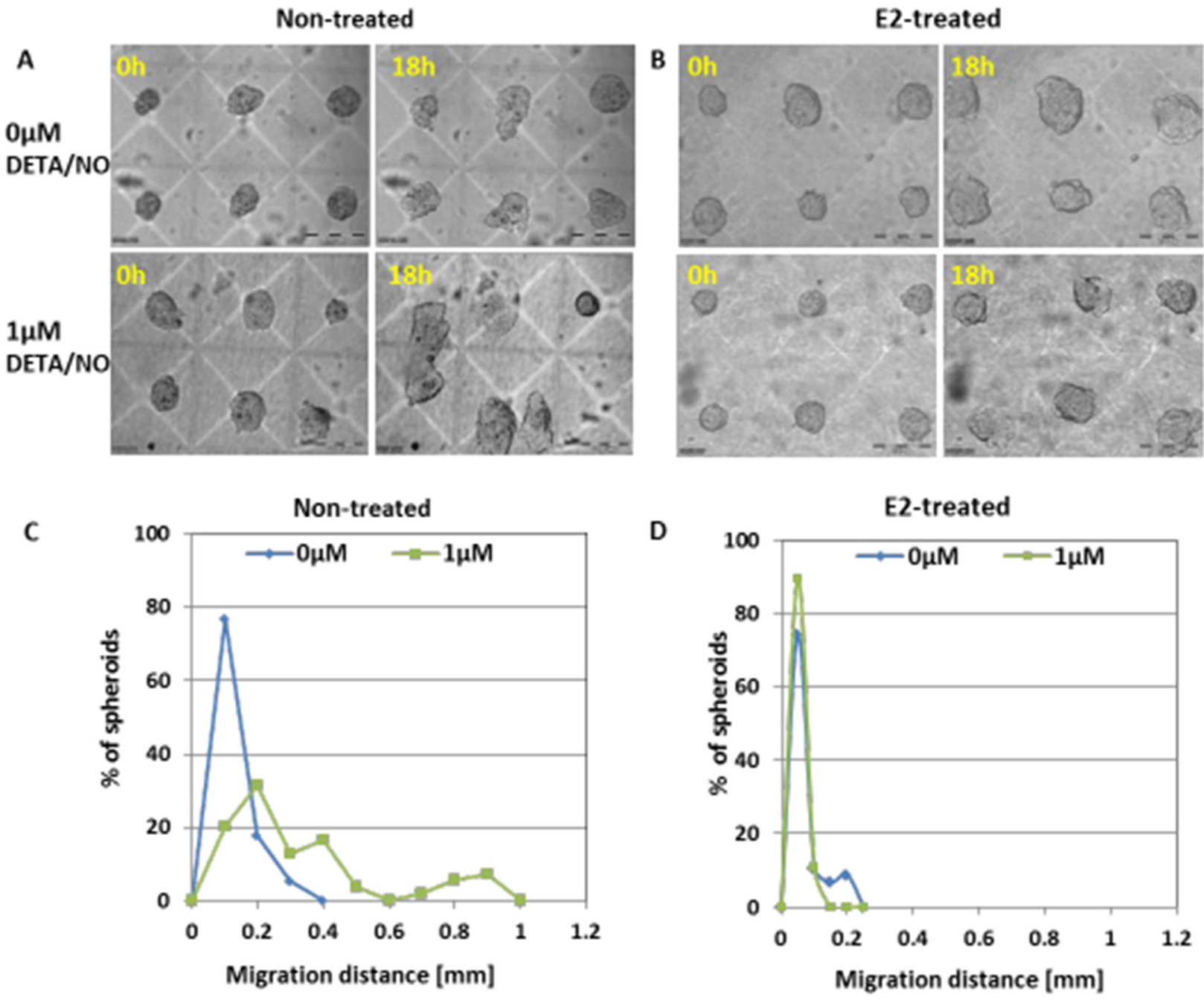

Figure 9: Invasion capacity of MCF7 BC spheroids. Changes in morphology and location of representative non-treated (A) and E2-treated (B) 2-day BC spheroids embedded within collagen matrix and cultured for $18 \mathrm{~h}$ in the presence and in the absence of $1 \mu \mathrm{M}$ DETA/NO. Scale bar $=200 \mu \mathrm{m}$. Distribution histograms of the averaged migration distance of hormone-deprived (C) and E2-treated (D) $\mathrm{BC}$ spheroids over an $18 \mathrm{~h}$ period in collagen matrix in the presence and in the absence of $1 \mu \mathrm{M}$ DETA/NO. 
migration is characterized by the migration of whole groups of cells interconnected by adhesion molecules and other communication junctions [33]. A hybrid epithelial/ mesenchymal (hybrid E/M) phenotype is associated with this type of migration. Although an increase in vimentin, a requisite regulator of mesenchymal cell migration, was reported here, more tests are needed in order to comprehend the EMT status of NO-induced invasive BC phenotype.

\section{DISCUSSION}

It is estimated that during the next 15 years there will be a $50 \%$ increase in the incidence of $\mathrm{BC}$, mainly

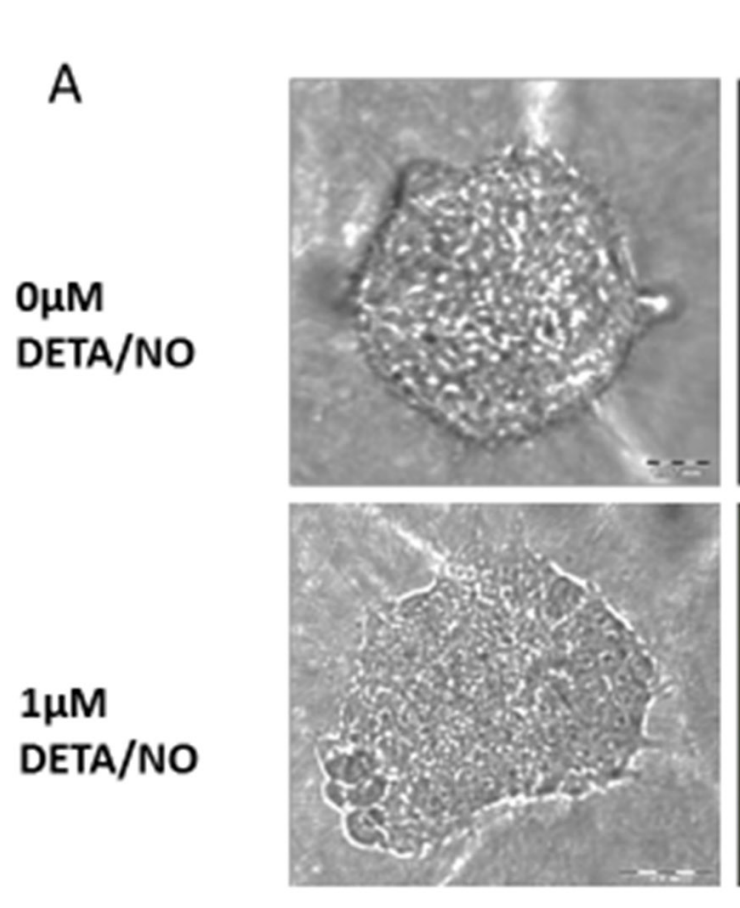

\section{Anti CXCR4-PE}
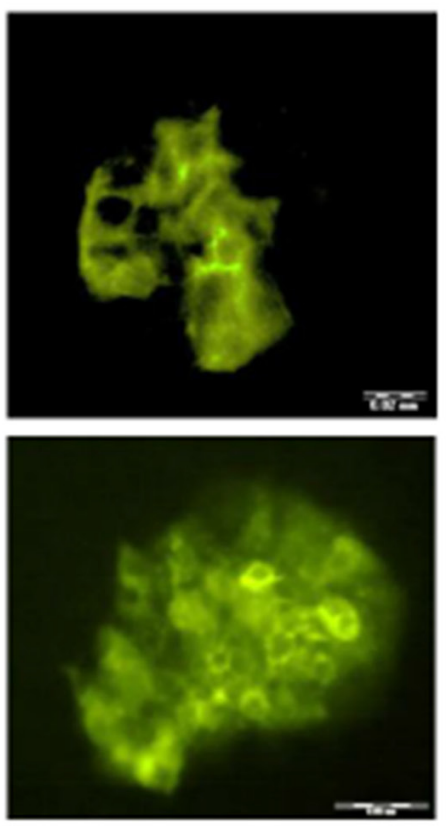

\section{Anti Vimentin-FITC}
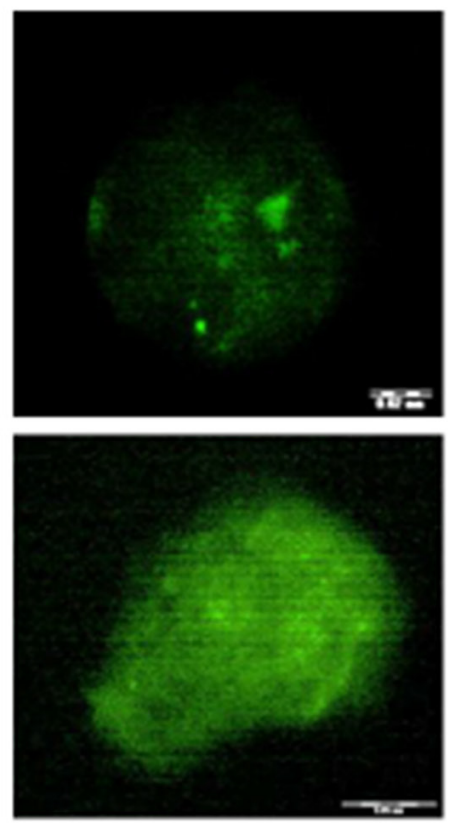

B

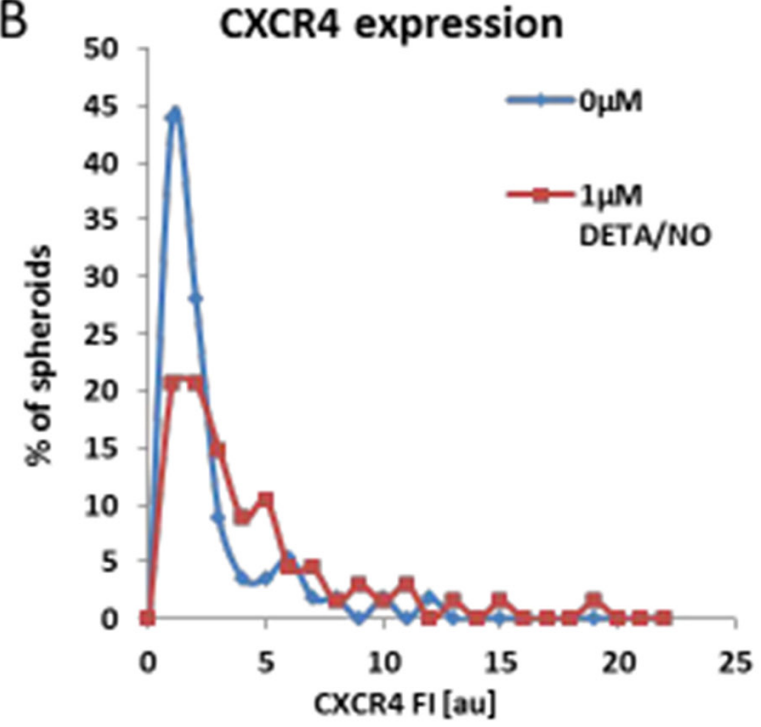

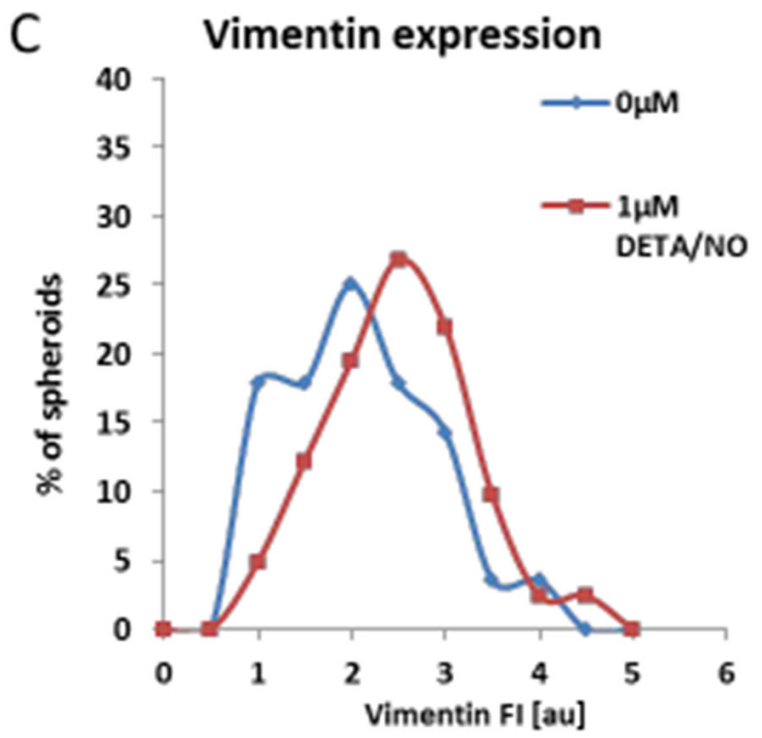

Figure 10: Expression levels of cellular proteins upon NO-induced migration. Hormone deprived BC spheroids were embedded within collagen matrix and cultured for $24 \mathrm{~h}$ in the absence (upper panel) and in the presence (lower panel) of $1 \mu \mathrm{M}$ DETA/NO. Then, live spheroids were stained by anti CXCR4 Abs, followed by fixation, permeabilization and additional staining by anti-vimentin Abs. (A) Bright field and corresponding fluorescence images of representative 2-day BC spheroids double stained for CXCR4 and vimentin are shown. Scale bar $=200 \mu \mathrm{m}$. Distribution histograms of CXCR4 (B) and vimentin (C) expression levels in individual hormone deprived MCF7 3D structures upon 24h exposure to DETA/NO. 
in ER-positive, which will become $95 \%$ of this disease, while only $5 \%$ will be ER-negative [34]. Strategies to prevent or cure ER-positive BC are an important priority in healthcare. The biology of estrogen-induced apoptosis has created a need for therapeutic approaches to block cell survival pathways in order to augment hormoneinduced apoptosis and to provide an inexpensive targeted therapy to maintain ER-positive BC patients indefinitely. However, the lack of biomimetic in vitro models that can recapitulate the features of solid tumors impedes the development of such new therapies. In order to overcome the significant distinctions in drug sensitivity between conventional 2D cell culture and 3D tumor multi cellular structures [35], as well as the substantial differences that exist between rodent and human NOS and the NO fluxes [36], a sensitive human BC spheroid model was used in the current study. This unique $3 \mathrm{D}$ culture system is utilized for the first time, to assess NO effects on hormone vulnerable BC cells. Using this cellular model, we were able to demonstrate that low doses of NO-donor induce cell proliferation, high metabolic activity, downregulation of ER and collective invasion in $\mathrm{BC}$ spheroids that are sensitive to estrogeninduced apoptosis, thus contributing to more aggressive phenotypes. Moreover, following hormone addition, 3D $\mathrm{BC}$ clusters were rescued from E2-induced apoptosis by these low concentrations of NO-donor, since NO attenuated the level of PS externalization, cell death and increased metabolic activity. NO cytoprotection involves modulation of the IAP protein, survivin, since low doses of the NO-donor considerably upregulate its expression.

Collectively, the results may suggest that NO, in nanomolar concentrations, is an inhibitor of estrogeninduced apoptosis and thus, plays a major role in this hormonal therapy.

In line with the above results, Fetz et al [37] showed that low NO levels conferred survivin-mediated resistance against cisplatin/taxol-induced apoptosis in head and neck squamous cell carcinoma lines. Additionally, endogenous NO was shown to be involved in tamoxifen-resistance in ER-positive BC [38], since it was essential for the completion of autophagy and the protection of $\mathrm{ER}^{+} \mathrm{MCF} 7$ $\mathrm{BC}$ cells from tamoxifen-induced cytotoxicity.

Importantly, in MCF10A, a non-tumorigenic mammary epithelial cell line, estrogen-induced apoptosis mediated by extranuclear ERs was blocked by NO via the cGMP pathway [39]. This may suggest that BC cells use existing mechanisms that occur in the normal breast epithelium, in addition to tumor-specific mechanisms which arise from genetic alteration such as chromosomal instability and mutated enzymes.

Furthermore, human BC lines, and especially the MCF7 line, are not single entities, but are rather comprised of large numbers of individual phenotypes that differ in gene expression profile, receptor expression and signaling pathway usage. Dominant phenotype proportions may be maintained by growth conditions such as the presence of hormones. This heterogeneity is likely attributed to all human $\mathrm{BC}$ cell lines, as well as to human BCs growing in vivo [40], and probably affects the overall response. The HMC array methodology described herein facilitates formation, treatment and monitoring of individual multicellular structures from a distinct small number of cells seeded in each MC, thus enabling analysis at single element resolution and, as a result, a high assay sensitivity. Due to the latter, specific sub-populations of spheroids that would go undetected in population-based measurements were revealed, allowing the study of tumor heterogeneity. Although not in the scope of this work, HMC technology also promotes retrieval of specific spheroids for molecular study of the different pathways that occur during NO regulation of BC growth.

In the current study, low doses of DETA/NO considerably downregulated the expression levels of ER within a period of $24 \mathrm{~h}$, probably through the post transcriptional process. Modulation of gene expression by NO has been demonstrated by others either indirectly by inhibiting NOS [17], or directly by using NO releasing agents [41]. Moreover, histone posttranslational modification was found to be the mechanism that supports gene expression modulation by NO [42]. Nevertheless, to the best of our knowledge, regulation of ER gene expression by NO has not been reported yet.

$\mathrm{NO}$ is a versatile and pleiotropic molecule. Generation of NO by its various NOSs in normal and malignant tissue is involved in cell signaling, and regulates a variety of physiological functions including cell survival, differentiation and death [43]. In cancer, the biological effects of NO are based not only on tumor type, but are mainly governed by their cellular concentrations along with spatial and temporal distribution both within tumor cells and in the tumor microenvironment.

At low concentrations $(<100 \mathrm{nM})$, NO has been reported to manifest a pathological phenotype characterized by increased proliferation, invasion and metastasis, stimulation of angiogenesis and inhibition of apoptosis. At super-physiological concentrations $(<400 \mathrm{nM})$, a less aggressive phenotype is evident, where metastasis and angiogenesis are inhibited, and apoptotic machinery operates appropriately [43, 44].

Utilizing a 3D culture system, the current study uniquely demonstrates a biphasic effect of NO on a specific phenotype, vulnerable to estrogen-induced apoptosis. In hormone deprived $\mathrm{BC}$ spheroids, $\mathrm{NO}$, at a nanomolar level, stimulated tumor progression and invasion; while higher NO concentrations (100nM) inhibited cell growth and metabolism and promoted mitochondrial mediated apoptosis. Following exposure to estrogen, a low dose of NO-donor represses apoptosis, while higher NO concentrations induce mixed effects on hormone treated $\mathrm{BC}$ phenotype; reduced proliferation and metabolic activity, as well as downregulation of survivin levels on the one hand, with inhibition of PS externalization on the other. 
Table 1: Oligonucleotide primers used for PCR

\begin{tabular}{|c|c|c|c|}
\hline \multirow[t]{2}{*}{ Target genes } & \multicolumn{2}{|c|}{ Primer sequence 5'------------3' } & \multirow[t]{2}{*}{ Product size (bp) } \\
\hline & Forward & Reverse & \\
\hline$\beta$-actin & АСТСТTCCAGCCTTCСТTCC & CCTGCTTGCTGATCCACATC & 302 \\
\hline ESR1-set 1 & AGACATGAGAGCTGCCAACC & GCCAGGCACATTCTAGAAGG & 299 \\
\hline ESR1-set 2 & TGAAGTGCAAGAACGTGGTG & AGCAAGCAAATGAATGGCCA & 357 \\
\hline
\end{tabular}

NO concentrations and their influences upon tumor cells are complicated by threshold amounts. Based on several reports of NO measurement in tissues, and from exogenous NO donors, it has been established that normal NO levels are generally below 50nM [44, 45]. The estimation of NO levels in hormone susceptible MCF7 spheroids showed compatible results. The basic difference in $\mathrm{NO}$ content found in the two BC phenotypes may account for at least some of the differences in their response to exogenous $\mathrm{NO}$, since it has been demonstrated that select signal transduction cascades respond to NO exposure with different threshold sensitivities, resulting in distinct phenotypic reactions. Hence, Thomas D et al [46] showed that low NO doses of 10-300 nM induced ERK phosphorylation and HIF-1 $\alpha$ (hypoxia induced factor $1 \alpha$ ) accumulation in MCF-7 cells, resulting in tumor proliferation and differentiation, while with high doses of NO (> $300 \mathrm{nM})$, p53 phosphorylation occurs, which is associated with apoptosis induction [46].

Interestingly, inhibition of hormone-induced apoptosis and other cyto-protective actions occur here, at the very low $(\sim 1 \mathrm{nM}) \mathrm{NO}$ level.

It is now widely recognized that many tumors utilize low-flux NO to resist apoptosis, stimulate expansion through accelerated proliferation and migration/invasion, and to resist eradication by anti-tumor therapies such as PDT as well. This low-flux NO can be generated by tumor cells per se, but surrounding vascular cells such as eNOSexpressing endothelial cells may also be a contributing factor in their generation [29].

These negative and potentially tumor-promoting side effects of NO, at least in PDT and possibly in other therapeutic strategies, may be averted through use of iNOS inhibitors as adjuvants [47].

The role of hyponitroxia (persistently low NO concentrations) as a key mediator in tumor progression has recently been discussed [48] and may become a novel therapeutic target to treat cancer and provide new opportunities for pharmacological intervention [49].

\section{MATERIALS AND METHODS}

\section{Materials}

Low-melt agarose (LMA) was obtained from Cambrex Bio Science Rockland, Inc. (Rockland,
ME USA). LMA was dissolved in phosphate buffer saline (PBS) at room temperature (RT) (stock solution concentration $6 \%$ ) and sterilized in an autoclave. Sylgard 184 Kit was purchased from Dow Corning Corp. (Midland, MI, USA).

Six or 24 microwell glass bottom plates were purchased from In Vitro Scientific (Sunnyvale, CA, USA).

RPMI, medium, Dulbecco's Modified Eagle's Medium (DMEM), heat-inactivated fetal calf serum (FCS), penicillin, streptomycin, sodium pyruvate and PBS were obtained from Biological Industries (Kibbutz Beit Haemek, Israel). DiethylenetriamineNONOate (DETA/NO) was obtained from Enzo Life Sciences (Farmingdale, NY, USA) and the stock solution $(10 \mathrm{mM})$ in PBS was kept at $-80^{\circ} \mathrm{C}$.

Anti-ER $\alpha$ and anti- $\beta$-Actin mouse monoclonal IgG antibodies, secondary goat anti-mouse IgGHRP and IgG-FITC, and collagen type 1 (rat) and 4,5-diaminofluorescein diacetate (DAF-2DA) were obtained from Santa Cruz Biotechnology (Santa Cruz, CA, USA). Anti-survivin-PE, anti-CXCR4$\mathrm{PE}$ and anti-cytochrome c-FITC human monoclonal IgG antibodies were purchased from Miltenyi Biotec (Germany). Collagen solution $(3 \mathrm{mg} / \mathrm{ml})$ was prepared on ice and the $\mathrm{pH}$ was adjusted to 7.4 using $\mathrm{NaOH}$, PBSx 10 and sterile DDW according to manufacturer's instructions.

17 $\beta$-estradiol (E2), propidium iodide (PI), tetramethylrhodamine methyl ester perchlorate (TMRM), Ponceau S solution and N $\omega$-nitro-L-arginine methyl ester (L-NAME) were purchased from SigmaAldrich Israel Ltd. (Rehovot, Israel). Hoechst 33342 dye trihydrochloride, trihydrate was obtained from Invitrogen-Molecular probes (Carlsbad, CA, USA). Apoptotic cells were detected using Annexin V-FITC Apoptosis Detection Kit (BioVision, USA) and NucView ${ }^{\mathrm{TM}} 488$ Caspase-3 Assay Kit (Biotium, Inc, Fremont, CA, USA).

Lowry assay kit and SuperSignal ${ }^{\mathrm{TM}}$ West Pico Chemiluminescent Substrate were purchased from ThermoFisher Scientific (USA).

Design and fabrication of hydrogel array and imaging device, as well as cell loading and spheroid generation are described in Supplementary Material 4. 


\section{MCF7 cell line vulnerable to E2-induced apoptosis}

MCF7 human BC cell line was cultured for more than 5 years in DMEM with $10 \%$ heat-inactivated FCS, $100 \mathrm{U} / \mathrm{mL}$ penicillin, $100 \mu \mathrm{g} / \mathrm{mL}$ streptomycin, $2 \%$ glutamine, 2\% sodium pyruvate (DMEM complete medium) without hormonal supplementation. The cells were incubated under standard cell culture conditions at $37^{\circ} \mathrm{C}, 5 \% \mathrm{CO}_{2}$ in humidified incubators. For E2 treatment, MCF7 cells were maintained in DMEM complete medium supplemented with $10^{-9} \mathrm{M}$ E2 for 5 weeks, E2 stock was in $100 \%$ ethanol, final concentration of ethanol was $0.002 \%$. E2-treated cells were used in experiments after 5-8 passages.

\section{DETA/NO treatment}

Following $48 \mathrm{~h}$ of growth, the spheroids were exposed to DETA/NO $(0.5-200 \mu \mathrm{M})$ in DMEM for $24 \mathrm{~h}$ at $37^{\circ} \mathrm{C}$ in a $\mathrm{CO}_{2}$ humidified incubator. DETA/NO decomposes spontaneously in aqueous media, releasing two mol of NO per mol of parent compound. Under conditions used here ( $\mathrm{pH} 7.4$ and $\left.37^{\circ} \mathrm{C}\right)$, the half-life of DETA/NO is about $24 \mathrm{~h}$. The amount of NO generated from DETA/NO in DMEM was measured [50] and the steady state concentrations of $\mathrm{NO}$ estimated at about $100 \mathrm{nM}$ and $1 \mathrm{nM}$ for $100 \mu \mathrm{M}$ and $1 \mu \mathrm{M}$ DETA/NO respectively [50].

\section{Fluorescent staining}

Mitochondrial membrane potential was measured by TMRM staining. For in-HMC array TMRM staining, the medium was removed from the macro-well and replaced with the same volume of medium containing $12.5 \mathrm{nM}$ TMRM. Spheroids were incubated for $1 \mathrm{~h}$ at $37^{\circ} \mathrm{C}$ under humidified atmosphere with $5 \% \mathrm{CO}_{2}$, then washed twice, and imaged. For quantitative analysis of the overall mitochondrial membrane potential of 3D spheroids under experimental conditions, the same spheroid population was stained twice at two time points, before and after $24 \mathrm{~h}$ treatment, and imaged. The following parameters were obtained: TMRM Fluorescence Intensity (FI); the averaged FI of all the pixels within a spheroid area, TMRM CV; the coefficient of variation (CV) of pixel intensity within a spheroid area and TMRM ratio; the ratio between TMRM FI of a spheroid at two time points. A detailed analysis of TMRM fluorescence parameters for mitochondrial membrane potential is described in Supplementary Material 2.

Cell nuclei were stained with Hoechst 33342 dye by incubating the spheroids in the presence of the probe at final concentration of $1 \mu \mathrm{g} / \mathrm{mL}$ for $1 \mathrm{~h}$ at $37^{\circ} \mathrm{C}$ under humidified atmosphere with $5 \% \mathrm{CO}_{2}$ followed by washing and imaging. For in-HMC array double (Hoechst 33342 and TMRM) spheroid staining, the entire medium was removed and exchanged with medium containing both probes in their final concentrations.

To assure uniform cell staining across the 3D cell clusters under the above conditions, images were acquired in $8 \mu \mathrm{m}$ increments along the spheroid $\mathrm{z}$ axis, and the mean FI of all pixels within each focal plane were calculated. For both probes (TMRM and Hoechst 33342), the CV of mean FI (CV FI) of the different focal planes $(n=100$ spheroids) did not exceed $8 \pm 2.6 \%$, indicating homogeneous staining of the $3 \mathrm{D}$ objects.

Apoptosis was evaluated by Annexin V test. The entire medium was removed and $50 \mu \mathrm{L}$ of binding buffer (HEPES buffer, $\mathrm{pH}$ 7.4) with Annexin V-FITC (final concentration of $1 \mathrm{mg} / \mathrm{ml}$ ) was added to spheroids within the MCs for $15 \mathrm{~min}$ in the dark at RT. The average FI of all pixels within a spheroid area was calculated. The cutoff value for Annexin V-positive spheroids was mean FI+SD of control unstained spheroid population $(\mathrm{n}=100)$.

In order to dye the same spheroids with both TMRM and Annexin V probes, cell clusters were successively stained, first with TMRM (as described above), then washed twice and stained with Annexin V-FITC.

For the estimation of the relative intracellular NO concentration in $3 \mathrm{D}$ spheroids, the medium was removed and replaced with the same volume of medium containing $10 \mu \mathrm{M}$ DAF-2DA for $30 \mathrm{~min}$ at $37^{\circ} \mathrm{C}$ in a $\mathrm{CO}_{2}$ humidified incubator. Then, spheroids were washed by exchanging the medium twice, and imaged. The FI of individual 3D spheroids were extracted by image analysis and the population averaged intracellular FI was calculated.

For control measurements, the DAF-2DA staining was performed in the presence of the NOS inhibitor L-NAME $(10 \mu \mathrm{M})$. A detailed analysis of NO content by DAF-2DA probe is described in Supplementary Material 3.

Caspase-3 activity was evaluated by exposing 3D clusters to NucView 488 substrate $(5 \mu \mathrm{M}, 90 \mathrm{~min})$ at $37^{\circ} \mathrm{C}$ in a $\mathrm{CO}_{2}$ humidified incubator, followed by imaging. The average FI within each spheroid was then, calculated.

\section{Immunofluorescent staining}

Immunofluorescence staining of ER and survivin was carried out following spheroid fixation within HMC array. Upon completion of vital measurements, the entire medium was removed from the macrowell and the spheroids were fixed within MCs by adding 4\% formaldehyde for $1 \mathrm{~h}$ at RT. Then, the cells were permeabilized for $15 \mathrm{~min}$ at RT with $0.1 \%$ Triton 100 in PBS, washed with PBS, and blocked with $4 \%$ BSA in PBS for $1 \mathrm{~h}$ at RT. Fixed spheroids were washed again, incubated in PBS containing anti-ER $\alpha \mathrm{mAb}(1: 100)$ for $24 \mathrm{~h}$ at $4{ }^{\circ} \mathrm{C}$, and then with FITC-conjugated anti-mouse $\operatorname{IgG}(1: 100)$ for $3 \mathrm{~h}$ at RT. Direct staining by anti-survivin-PE $\mathrm{mAb}(1: 10)$ was performed by incubation at $4^{\circ} \mathrm{C}$ for $24 \mathrm{~h}$.

The quantification of the release of cytochrome $\mathrm{c}$ from mitochondria into the cytosol on a per-spheroid basis 
was done as previously described [51]. Spheroids within HMC array were first permeabilized for $15 \mathrm{~min}$ by $0.1 \%$ saponin, a cholesterol-removing agent that affects the plasma membrane without disrupting mitochondrial membranes [52]. Then, the spheroids were fixed, blocked and directly stained by cytochrome c-FITC mAb (1:100) as described above.

Surface expression level of CXCR4 was evaluated in live spheroids. BC clusters were incubated in 4\% BSA in PBS for $1 \mathrm{~h}$ at RT, followed by direct staining with antiCXCR4-PE mAb $(1: 10)$ for $2 \mathrm{~h}$ at $4^{\circ} \mathrm{C}$. At the end of the staining process, spheroids were washed twice with $0.5 \%$ BSA in PBS.

\section{Tumor cell invasion assay in 3D BC spheroid model}

For analysis of invasion capacity, MCF7 BC spheroids were embedded in an extracellular matrix composed of type I rat tail collagen. Two-day BC spheroids generated within HMC array-based plate, were cooled on ice for $10 \mathrm{~min}$, and embedded in collagen by replacing the entire medium above the array with a cold collagen solution $(150 \mu 1)$. Then, the plate was transferred to a tissue culture incubator for $1 \mathrm{~h}$, to promote collagen gelation. Following collagen gelation, $300 \mu \mathrm{l}$ of the warmed $\left(37^{\circ} \mathrm{C}\right) 1 \%$ LMA was poured on top of the collagen gel and the array was incubated first at RT for $5-7 \mathrm{~min}$ and then for $2 \mathrm{~min}$ at $4^{\circ} \mathrm{C}$, for agarose gelation. The agarose layer prevents detachment of the collagen-gel matrix. Finally, 1-3ml of warm cell culture medium, with or without invasion modulating compounds, was added.

\section{Western blot analysis}

Hormone-treated and untreated MCF7 cells and spheroids were collected, washed twice with ice-cold PBS, lysed in lysis buffer (10mM Tris-HCL, pH=7.4, $1 \mathrm{mM}$ EDTA, 0.5mM EGTA, 150mM NaCl, 1\% Triton X-100, $0.1 \%$ SDS, $0.1 \%$ Na deoxycholate, $1 \mathrm{mM}$ protease inhibitor PMSF) for $30 \mathrm{~min}$ on ice and centrifuged at $14000 \mathrm{~g}$ for $15 \mathrm{~min}$ at $4^{\circ} \mathrm{C}$. Protein samples $(20-50 \mu \mathrm{g}$ in different experiments) were separated by sodium dodecyl sulfatepolyacrylamide gel electrophoresis (SDS-PAGE) and transferred to nitrocellulose membrane. The membranes were stained with Ponceau S, blocked with 5\% non-fat milk in PBS, $0.05 \%$ Tween 20 (PBST) for $1.5 \mathrm{~h}$ at RT and incubated with the primary $\mathrm{ER} \alpha$ antibody $(1: 500)$ at $4^{\circ} \mathrm{C}$ overnight. The membranes were then rinsed in PBST and incubated with secondary IgG-HRP antibodies (1:5000) for $3 \mathrm{~h}$ at RT. After washing, proteins were detected using SuperSignal $^{\mathrm{TM}}$ West Pico Chemiluminescent Substrate Membranes were reprobed with anti-Actin antibodies (1:500).

Background signal was subtracted from the images acquired by western chemiluminescence machine
(ImageQuant LAS 4000 mini, GE Healthcare, USA) and the bend area was measured using intensity threshold. All signals above background plus SD were counted.

\section{RT-PCR}

Total cellular RNA from 3-day MCF7 spheroids, was extracted with a TRI Reagent ${ }^{\circledR}$ RNA extraction kit, Sigma-Aldrich Israel Ltd. (Rehovot, Israel), according to manufacturer instructions. RNA pellet was dissolved by ultra-pure water. Total RNA was subjected to PerfeCTa DNase I of Quanta Biosciences Inc. (Beverly, MA, USA) in order to eliminate genomic DNA from samples. For RT reaction, $1 \mu \mathrm{g}$ of genomic DNA-free RNA from each sample was used to synthesize cDNA, by using qScript cDNA Synthesis Kit, Quanta Biosciences Inc. (Beverly, MA, USA) according to manufacturer instructions. Oligonucleotide primers for PCR were designed using Primer3 software and synthesized by IDT (Leuven, Belgium) are shown in Table 1:

cDNA (1/7) were taken for PCR amplification, $0.4 \mu \mathrm{M}$ of each primer at a final volume of $25 \mu \mathrm{l}$, using GoTaq G2 Green Master Mix from Promega Corporation (Madison, WI, USA). PCR program is as follows: after initial denaturation at $94^{\circ} \mathrm{C}$ for $2 \mathrm{~min}, 30$ cycles of denaturation (at $94^{\circ} \mathrm{C}$ for $45 \mathrm{~s}$ ), annealing (at $59^{\circ} \mathrm{C}$ for $30 \mathrm{~s}$ ) and extension (at $73^{\circ} \mathrm{C}$ for $30 \mathrm{~s}$ ), a final extension was performed for $5 \mathrm{~min}$. Visualization of the RT-PCR products was done using 1.5\% agarose gel stained with SYBR TM Safe DNA Gel Stain, Thermo Fisher Scientific Inc. (USA). Gel images were obtained using DNR Bio Imaging System MiniLumi UV-image analyzer (Ma'ale HaHamisha, Jerusalem, Israel), and the densities of the products were quantified using Image J analysis software. The relative expression levels were calculated as the density of the product of ESR1 divided by that of the $\beta$-actin from the same cDNA.

\section{Image acquisition and analysis}

Imaging system and operating software have been previously described (see Supplementary Material 4 for details). For optical data acquisition and analysis, each set of image acquisitions commenced with acquiring the bright field image of a chosen view field, followed by the acquisition of several fluorescent images, one for each fluorescent probe, taken at different preset time points. A series of regions on the array was chosen and the motorized stage configured to stop at these locations/ positions. The initial cell distribution in these regions was imaged and the MC walls maintained the position of each group/individual cell within its $\mathrm{MC}$, guaranteeing that these stage positions represented the same individual groups of cells throughout the experiment. For continuous monitoring of the spheroid formation process, and the course of NO treatment as well, the imaging system 
was programmed to take images of each saved position automatically at consistent time intervals, and the six-well plate was either left on the microscope stage or placed in an external incubator and then returned to the microscope, verifying that the same regions were scanned, and images of the same spheroids taken.

Spheroids were automatically defined as objects or regions of interest (ROIs) by Sobel edge detection algorithm, and their sectional area was outlined on the bright field image. Then, on each fluorescent wide field image, ROIs were determined by mapping those outlines on the interrogated fluorescent field image. Next, the fluorescent background, determined by averaging the FI detected by camera pixels found between the outlined regions, was subtracted from the fluorescent image. It should be emphasized that determination of background signal and its subtraction from the fluorescent image were performed separately for each of the acquired fluorescent field images. Then, the fluorescent images underwent thresholding, and two parameters were calculated: the mean FI value obtained for each ROI (mean FI of all pixels within a ROI that are within the threshold borders) and the area fraction of the fluorescent signal (area percentage of all FI-positive pixels of a ROI, relative to the area of a $\mathrm{ROI})$ were calculated using Cell ${ }^{\wedge} \mathrm{P}$ software.

Morphometric parameters of spheroids were extracted by several image-processing algorithms based on probe-free bright-field microscopy. These include automatic algorithms for MC identification, spheroid segmentation, sphericity or 'roundness' of a spheroid and texture-based distinction like smoothness value (e.g. entropy, SD and range of gray values). Size and volume estimation of individual cells and spheroids, as well as the number of cells that comprise each spheroid and calculation of doubling time were done as described in Supplementary Material 1.

For analysis of the 3D structure collective migration, the $\mathrm{X}$ and $\mathrm{Y}$ coordinates of the center of each ROI/spheroid were determined by $\mathrm{Cell}^{\wedge} \mathrm{P}$ software at two time points, before $(\mathrm{X} 1, \mathrm{Y} 1)$ and after $(\mathrm{X} 2, \mathrm{Y} 2)$ invasion assay. Then, the distance $(\mathrm{d})$ of spheroid migration was calculated as $\mathrm{d}=\sqrt{ }\left((\mathrm{X} 1-\mathrm{X} 2)^{2}+(\mathrm{Y} 1-\mathrm{Y} 2)^{2}\right)$. The K-means algorithm was used for clustering cells groups.

\section{Statistical analysis}

Each test was performed in duplicate (2 macrowells). Fifteen to thirty images $(\times 10$ magnification $)$ from different areas within the array were acquired, yielding about 200 individual MCs and the corresponding spheroids per single macro-well. Although the variability of both the morphology and fluorescence parameters within spheroid populations was very high, most of the measured parameters showed normal distribution. The mean and standard deviation (SD) for each measured parameter was calculated for the various spheroid/cell populations under investigation.

Comparison between groups was performed using the t-test, ANOVA and MANOVA for groups with Gaussian distributions, or non-parametric tests (Wilcoxon, Kruskal-Wallis and van der Waerden) for small groups. A paired two sample for means t-test was used to compare two groups of cell-clusters before and after treatment. Statistical significance of differences was determined at $\mathrm{p}<0.05$.

\section{Abbreviations}

BC breast cancer
CV coefficient of variation
DETA/NO diethylenetriamineNONOate
DMEM Dulbecco's Modified Eagle's Medium
E2 $17 \beta$-estradiol
ECM extra-cellular matrix
EMT epithelial-mesenchymal transition
ER estrogen receptor
FCS fetal calf serum
FI Fluorescence Intensity
GR growth ratio
HMC hydrogel microchamber
HP high-proliferating
IAP inhibitor of apoptosis
LMA low-melt agarose
LP low-proliferating
MC microchamber
NO nitric oxide
NOS NO synthase
PBS phosphate buffer saline
PBST PBS, 0.05\% Tween 20
PDMS polydimethylsiloxane
PI propidium iodide
PS phosphatidylserine
ROI region of interest
RT room temperature
RT-PCR reverse transcription polymerase chain
reaction
SD standard deviation
TMRM tetramethylrhodamine
perchlorate

\section{Author contributions}

Yana Shafran led this study and carried out image and western blot measurements, image analysis and assessment of the results. She performed the literature survey and drafted the manuscript.

Naomi Zurgil led and supervised this study, including its experimental design, the process of image analysis, evaluation of results and manuscript drafting and preparation. 
Maria Sobolev was responsible for culturing and testing of breast cancer phenotypes and for design of the $\mathrm{HMC}$ array and its production.

Elena Afrimzon contributed to in-HMC generation and culturing of breast cancer spheroids, and their postfixation histological examination. She participated in drafting the manuscript.

Orit Ravid-Hermesh led the molecular analysis of ER and the development of spheroid invasion assay. She participated in drafting the manuscript.

Yaron Hakuk was responsible for software programs and contributed to image analysis.

Asher Shainberg supervised this study and drafted the manuscript.

Mordechai Deutsch supervised this study, designed and coordinated HMC array production and drafted the manuscript.

The manuscript has been read and approved by all named authors and there are no other persons who satisfy the criteria for authorship who are not listed.

\section{ACKNOWLEDGMENTS}

This study was endowed by the Bequest of MosheShimon and Judith Weisbrodt.

We wish to thank Sergei Moshkov for his valuable technical support.

\section{CONFLICTS OF INTEREST}

The authors declare that they have no conflicts of interest.

\section{FUNDING}

There has been no significant financial support for this work that could have influenced its outcome.

\section{REFERENCES}

1. DeSantis CE, Bray F, Ferlay J, Lortet-Tieulent J, Anderson $\mathrm{BO}$, Jemal A. International variation in female breast cancer incidence and mortality rates. Cancer Epidemiol Biomarkers Prev. 2015;24:1495-506.

2. Johnston SR. Enhancing endocrine therapy for hormone receptor-positive advanced breast cancer: cotargeting signaling pathways. J Natl Cancer Inst. 2015;107:djv212.

3. Early Breast Cancer Trialists' Collaborative Group (EBCTCG). Effects of chemotherapy and hormonal therapy for early breast cancer on recurrence and 15-year survival: an overview of the randomised trials. Lancet. 2005;365:1687-717.
4. Lønning PE, Eikesdal HP. Aromatase inhibition 2013: clinical state of the art and questions that remain to be solved. Endocr Relat Cancer. 2013;20:R183-201.

5. Osborne CK, Schiff R. Mechanisms of endocrine resistance in breast cancer. Ann Rev Med. 2011;62:233-47. https:// doi.org/10.1146/annurev-med-070909-182917.

6. Zhang C, Guan Y, Sun Y, Ai D, Guo Q. Tumor heterogeneity and circulating tumor cells. Cancer Lett. 2016;374:216-23.

7. Jordan VC. The new biology of estrogen-induced apoptosis applied to treat and prevent breast cancer. Endocr Relat Cancer. 2015;22:R1-31.

8. Coelingh Bennink HJ, Verhoeven C, Dutman AE, Thijssen $\mathrm{J}$. The use of high-dose estrogens for the treatment of breast cancer. Maturitas. 2017;95:11-23.

9. Kaklamani VG, Gradishar WJ. Endocrine therapy in the current management of postmenopausal estrogen receptor-positive metastatic breast cancer. Oncologist. 2017;22:507-17.

10. Jordan VC. Linking estrogen-induced apoptosis with decreases in mortality following long-term adjuvant tamoxifen therapy. J Natl Cancer Inst. 2014;106:dju296.

11. Suba Z. The pitfall of the transient, inconsistent anticancer capacity of antiestrogens and the mechanism of apparent antiestrogen resistance. Drug Des Devel Ther. 2015;9:4341-53.

12. Suba Z. Activating mutations of ESR1, BRCA1 and CYP19 aromatase genes confer tumor response in breast cancers treated with antiestrogens. Recent Pat Anticancer Drug Discov. 2017;12:136-47.

13. Jordan VC, Fan P, Abderrahman B, Maximov PY, Hawsawi YM, Bhattacharya P, Pokharel N. Sex steroid induced apoptosis as a rational strategy to treat antihormone resistant breast and prostate cancer. Discov Med. 2016;21:411-27.

14. Sweeney EE, Fan P, Jordan VC. Mechanisms underlying differential response to estrogen-induced apoptosis in longterm estrogen-deprived breast cancer cells. Int J Oncol. 2014;44:1529-38.

15. Fan P, Wang J, Santen RJ, Yue W. Long-term treatment with tamoxifen facilitates translocation of estrogen receptor $\alpha$ out of the nucleus and enhances its interaction with EGFR in MCF-7 breast cancer cells. Cancer Res. 2007;67:1352-60.

16. Fan P, Yue W, Wang JP, Aiyar S, Li Y, Kim TH, Santen RJ. Mechanisms of resistance to structurally diverse antiestrogens differ under premenopausal and postmenopausal conditions: evidence from in vitro breast cancer cell models. Endocrinology. 2009;150:2036-45.

17. Heinecke JL, Ridnour LA, Cheng RY, Switzer CH, Lizardo MM, Khanna C, Glynn SA, Hussain SP, Young HA, Ambs $\mathrm{S}$, Wink DA. Tumor microenvironment-based feed-forward regulation of NOS2 in breast cancer progression. Proc Natl Acad Sci U S A. 2014;111:6323-8. 
18. Pink JJ, Jordan VC. Models of estrogen receptor regulation by estrogens and antiestrogens in breast cancer cell lines. Cancer Res. 1996;56:2321-30.

19. Afrimzon E, Botchkina G, Zurgil N, Shafran Y, Sobolev M, Moshkov S, Ravid-Hermesh O, Ojima I, Deutsch M. Hydrogel microstructure live-cell array for multiplexed analyses of cancer stem cells, tumor heterogeneity and differential drug response at single-element resolution. Lab Chip. 2016;16:1047-62.

20. Lewis JS, Meeke K, Osipo C, Ross EA, Kidawi N, Li T, Bell E, Chandel NS, Jordan VC. Intrinsic mechanism of estradiol-induced apoptosis in breast cancer cells resistant to estrogen deprivation. J Natl Cancer Inst. 2005;97:1746-59.

21. Circu ML, Aw TY. Reactive oxygen species, cellular redox systems, and apoptosis. Free Radic Biol Med. 2010;48:749-62.

22. Liu H, Li Q, Wang Y, Hong H, Chen M, Wang Y, Hong F, Yang S. Elevated nitric oxide levels associated with hepatic cell apoptosis during liver injury. Hepatol Res. 2016.

23. Razavi HM, Hamilton JA, Feng Q. Modulation of apoptosis by nitric oxide: implications in myocardial ischemia and heart failure. Pharmacol Ther. 2005;106:147-62.

24. Garg H, Suri P, Gupta JC, Talwar GP, Dubey S. Survivin: a unique target for tumor therapy. Cancer Cell Int. 2016;16:49.

25. Chen X, Duan N, Zhang C, Zhang W. Survivin and tumorigenesis: molecular mechanisms and therapeutic strategies. J Cancer. 2016;7:314-23.

26. Singh M, Chaudhry P, Fabi F, Asselin E. Cisplatin-induced caspase activation mediates PTEN cleavage in ovarian cancer cells: a potential mechanism of chemoresistance. BMC Cancer. 2013;13:233.

27. Hayes DF, Paoletti C. Circulating tumour cells: insights into tumour heterogeneity. J Intern Med. 2013;274:137-43.

28. Babayan A, Hannemann J, Spötter J, Müller V, Pantel K, Joosse SA. Heterogeneity of estrogen receptor expression in circulating tumor cells from metastatic breast cancer patients. PLoS One. 2013;8:e75038.

29. Girotti AW. Modulation of the anti-tumor efficacy of photodynamic therapy by nitric oxide. Cancers (Basel). 2016;8:E96.

30. Xu C, Zhao H, Chen H, Yao Q. CXCR4 in breast cancer: oncogenic role and therapeutic targeting. Drug Des Devel Ther. 2015;9:4953-64.

31. Satelli A, Li S. Vimentin as a potential molecular target in cancer therapy or vimentin, an overview and its potential as a molecular target for cancer therapy. Cell Mol Life Sci. 2011;68:3033-46.

32. Vuoriluoto K, Haugen H, Kiviluoto S, Mpindi JP, Nevo J, Gjerdrum C, Tiron C, Lorens JB, Ivaska J. Vimentin regulates EMT induction by Slug and oncogenic H-Ras and migration by governing Axl expression in breast cancer. Oncogene. 2011;30:1436-48.
33. Krakhmal NV, Zavyalova MV, Denisov EV, Vtorushin SV, Perelmuter VM. Cancer invasion: patterns and mechanisms. Acta Naturae. 2015;7:17-28.

34. Rosenberg PS, Barker KA, Anderson WF. Estrogen receptor status and the future burden of invasive and in situ breast cancers in the United States. J Natl Cancer Inst. 2015;107:djv159.

35. Breslin S, O'Driscoll L. The relevance of using 3D cell cultures, in addition to $2 \mathrm{D}$ monolayer cultures, when evaluating breast cancer drug sensitivity and resistance. Oncotarget. 2016;7:45745-56. https://doi.org/10.18632/ oncotarget.9935.

36. Hoos MD, Vitek MP, Ridnour LA, Wilson J, Jansen M, Everhart A, Wink DA, Colton CA. The impact of human and mouse differences in NOS2 gene expression on the brain's redox and immune environment. Mol Neurodegener. 2014;9:50.

37. Fetz V, Bier C, Habtemichael N, Schuon R, Schweitzer A, Kunkel M, Engels K, Kovács AF, Schneider S, Mann W, Stauber RH, Knauer SK. Inducible NO synthase confers chemoresistance in head and neck cancer by modulating survivin. Int J Cancer. 2009;124:2033-41.

38. Duan L, Danzer B, Levenson VV, Maki CG. Critical roles for nitric oxide and ERK in the completion of prosurvival autophagy in 4OHTAM-treated estrogen receptor-positive breast cancer cells. Cancer Lett. 2014;353:290-300.

39. Kastrati I, Edirisinghe PD, Wijewickrama GT, Thatcher GR. Estrogen-induced apoptosis of breast epithelial cells is blocked by NO/cGMP and mediated by extranuclear estrogen receptors. Endocrinology. 2010;151:5602-16.

40. Gunduz M. Breast Cancer - Carcinogenesis, Cell Growth and Signalling Pathways. InTech; 2011. Available from: http://www.intechopen.com/books/breast-cancercarcinogenesis-cell-growth-and-signalling-pathways.

41. Cheng RY, Basudhar D, Ridnour LA, Heinecke JL, Kesarwala AH, Glynn S, Switzer CH, Ambs S, Miranda KM, Wink DA. Gene expression profiles of NO- and $\mathrm{HNO}$-donor treated breast cancer cells: insights into tumor response and resistance pathways. Nitric Oxide. 2014;43:17-28.

42. Vasudevan D, Hickok JR, Bovee RC, Pham V, Mantell LL, Bahroos N, Kanabar P, Cao XJ, MaienscheinCline M, Garcia BA, Thomas DD. Nitric oxide regulates gene expression in cancers by controlling histone posttranslational modifications. Cancer Res. 2015;75:5299-308.

43. Bonavida B, Garban H. Nitric oxide-mediated sensitization of resistant tumor cells to apoptosis by chemoimmunotherapeutics. Redox Biol. 2015;6:486-94.

44. Bonavida B, Baritaki S. Dual role of NO donors in the reversal of tumor cell resistance and EMT: downregulation

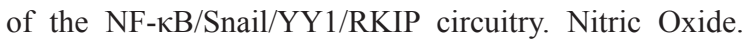
$2011 ; 24: 1-7$. 
45. Vanini F, Kashfi K, Nath N. The dual role of iNOS in cancer. Redox Biol. 2015;6:334-43.

46. Thomas DD, Espey MG, Ridnour LA, Hofseth LJ, Mancardi D, Harris CC, Wink DA. Hypoxic inducible factor $1 \alpha$, extracellular signal-regulated kinase, and p53 are regulated by distinct threshold concentrations of nitric oxide. Proc Natl Acad Sci U S A. 2004;101:8894-9.

47. Girotti AW, Fahey JM, Korytowski W. Multiple means by which nitric oxide can antagonize photodynamic therapy. Curr Med Chem. 2016;23:2754-69.

48. Oronsky B, Fanger GR, Oronsky N, Knox S, Scicinski J. The implications of hyponitroxia in cancer. Transl Oncol. 2014;7:167-73.

49. Vahora H, Khan MA, Alalami U, Hussain A. The potential role of nitric oxide in halting cancer progression through chemoprevention. J Cancer Prev. 2016;21:1-12.
50. Shafran Y, Zurgil N, Afrimzon E, Tauber Y, Sobolev M, Shainberg A, Deutsch M. Correlative analyses of nitric oxide generation rates and nitric oxide synthase levels in individual cells using a modular cell-retaining device. Anal Chem. 2012;84:7315-22.

51. Christensen ME, Jansen ES, Sanchez W, Waterhouse NJ. Flow cytometry based assays for the measurement of apoptosis-associated mitochondrial membrane depolarisation and cytochrome c release. Methods. 2013;61:138-45.

52. Clerc P, Ge SX, Hwang H, Waddell J, Roelofs BA, Karbowski M, Sesaki H, Polster BM. Drp1 is dispensable for apoptotic cytochrome c release in primed MCF10A and fibroblast cells but affects Bcl-2 antagonist-induced respiratory changes. Br J Pharmacol. 2014;171:1988-99. 